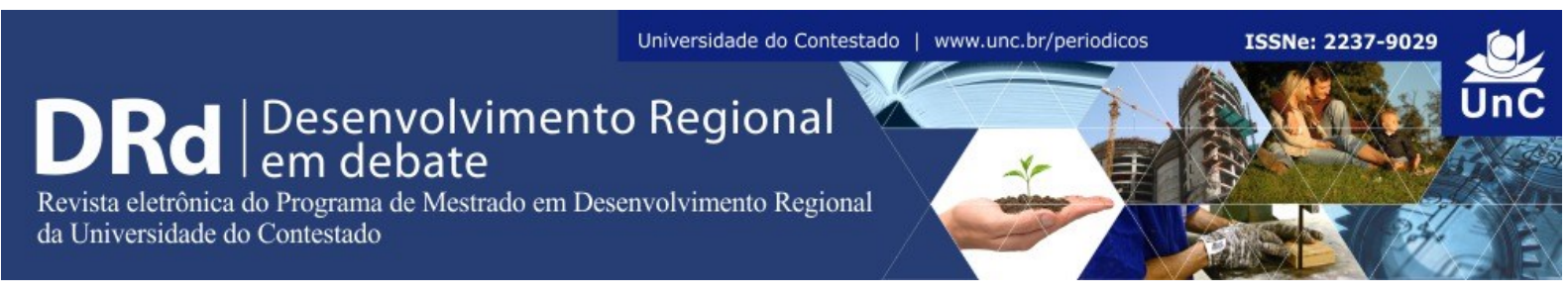

\title{
DISTRIBUIÇÃO DE RENDA NA AMAZÔNIA: UM ESTUDO DOS POLOS AGROFLORESTAIS EM RIO BRANCO - AC
}

\author{
Raimundo Cláudio Gomes Maciel ${ }^{1}$ \\ Pedro Gilberto Cavalcante Filho ${ }^{2}$ \\ Francisco Bezerra Lima Júnior ${ }^{3}$ \\ Elyson Ferreira Souza ${ }^{4}$
}

\begin{abstract}
RESUMO
Diante da dificuldade de reprodução social da produção familiar rural em assentamentos tradicionais criados pelo Instituto Nacional de Colonização e Reforma Agrária (INCRA), a Prefeitura Municipal de Rio Branco (PMRB) do Estado do Acre criou uma nova modalidade de assentamento na década de 1990, denominado Polo Agroflorestal, conhecido também como Cinturão Verde, com a finalidade de assentar antigos seringueiros e agricultores expropriados anteriormente. $\mathrm{O}$ presente trabalho tem por objetivo analisar a evolução da distribuição de renda no Cinturão Verde do município de Rio Branco em intervalo de dez anos. Especificamente, busca-se identificar a proporção de classes de renda na região, o valor de produção gerado e as condições do uso da terra. A hipótese adotada é que a criação do Polos Agroflorestais é fundamental para o fortalecimento da produção familiar rural de forma que contribua para o desenvolvimento da região, mediante a erradicação da pobreza e melhoria da distribuição de renda. A metodologia utilizada para realizar a avaliação econômica é desenvolvida e consolidada pelo Projeto de Análise Socioeconômica dos Sistemas Básicos de Produção Familiar Rural do Estado do Acre (ASPF) da Universidade Federal do Acre (UFAC). Os resultados mostraram que houve uma melhoria na distribuição de renda entre as famílias assentadas nos Polos Agroflorestais, porém, os índices de concentração de renda acompanham a realidade brasileira, mostrando-se ainda elevados.
\end{abstract}

Palavras-Chave: Amazônia. Distribuição de Renda. Polo Agroflorestal. Agricultura Familiar. Desenvolvimento Sustentável.

\footnotetext{
${ }^{1}$ Doutor em Economia Aplicada, professor da Universidade Federal do Acre (UFAC). Coordenador do Projeto de Análise Socioeconômica dos Sistemas Básicos de Produção Familiar Rural do Estado do Acre (ASPF). Rio Branco. Acre. Brasil. E-mail: rcgmaciel@ufac.br

${ }^{2}$ Economista pela Universidade Federal do Acre (UFAC). Pesquisador do Projeto de Análise Socioeconômica dos Sistemas Básicos de Produção Familiar Rural do Estado do Acre (ASPF). E-mail: pedro.gilberto@hotmail.com

${ }^{3}$ Mestre em Desenvolvimento Regional pela Universidade Federal do Acre (UFAC), Professor do Instituto Federal de Ciência, Tecnologia e Educação do Acre (IFAC). Pesquisador do Projeto de Análise Socioeconômica dos Sistemas Básicos de Produção Familiar Rural do Estado do Acre (ASPF). E-mail: francisco.junior@,ifac.edu.br

${ }^{4}$ Doutor em Economia Aplicada, professor do Centro de Ciências Jurídicas e Sociais Aplicadas (CCJSA) da Universidade Federal do Acre (UFAC). Pesquisador do Projeto de Análise Socioeconômica dos Sistemas Básicos de Produção Familiar Rural do Estado do Acre (ASPF). E-mail: elyson.souza@ufac.br
}

DRd - Desenvolvimento Regional em debate (ISSNe 2237-9029)

v. 8, n. 2, p. 108-142, jul./dez. 2018. 


\title{
DISTRIBUTION OF INCOME IN THE AMAZON: A STUDY OF THE AGROFLORESTAIS POLES IN RIO BRANCO - AC
}

\begin{abstract}
In the face of the difficulty of social reproduction of rural family production in traditional settlements created by the National Institute of Colonization and Agrarian Reform (INCRA), the Municipal Government of Rio Branco (PMRB) of the State of Acre created a new modality of settlement in the decade of 1990, called the Agroforestry Pole, also known as the Green Belt, in order to settle former rubber tappers and expropriated farmers previously. The present work has the aim of analyzing the evolution of the income distribution in the Green Belt of the municipality of Rio Branco in a period of ten years. Specifically, it is sought to identify the proportion of income classes in the region, the value of production generated and the conditions of land use. The hypothesis adopted is that the creation of agroforestry poles is fundamental for the strengthening of rural family production in a way that contributes to the development of the region by eradicating poverty and improving income distribution. The methodology used to carry out the economic evaluation is developed and consolidated by the Socioeconomic Analysis Project of the Basic Systems of Rural Family Production of the State of Acre (ASPF) of the Federal University of Acre (UFAC). The results showed that there was an improvement in the income distribution among the families settled in the Agroforestry Poles, however, the income concentration indices accompany the Brazilian reality, and are still high.
\end{abstract}

Keywords: Amazon. Income distribution. Agroforestry Pole. Family farming. Sustainable development.

\section{INTRODUÇÃO}

A partir da década de 1970, o Governo Militar impôs uma série de medidas pautadas nas teorias desenvolvimentistas na Amazônia que consistiam em ampliar a fronteira agrícola dessa região. Esse processo culminou em diversos problemas socioeconômicos e ambientais, principalmente, devido a desapropriação das populações tradicionais e a instalação de atividades madeireira e pecuarista (MACIEL, 2003; SOUZA, 2008).

É importante destacar que a atividade pecuarista é altamente concentradora de renda, bem como degradante ao meio ambiente e continua avançando sua fronteira até os dias atuais na Amazônia. Estudos apontam que as áreas de pastagens localizadas fora da Amazônia estão sendo substituídas por lavouras mais rentáveis como o algodão, grãos e cana de açúcar (NEHMI FILHO, 2005).

Nessa discussão, na Amazônia, é onde se encontram as maiores taxas de crescimento de rebanho bovino. Entre 1990 e 2006, estima-se que foram desmatados 30,6 milhões de hectares na região conforme dados do Instituto Nacional de Pesquisas Espaciais - INPE. Ao descontar desta área 5,3 milhões de hectares, que são destinadas a agricultura e reflorestamento, segundo dados do Instituto Brasileiro de Geografia e Estatística - IBGE,

DRd - Desenvolvimento Regional em debate (ISSNe 2237-9029) 
estima-se que aproximadamente 25,3 milhões de hectares de pastagens foram instaladas na Amazônia entre os anos 1990 e 2006 (BARRETO, 2008).

Para atenuar as questões socioeconômicas e ambientais, o Governo iniciou um processo de reforma agrária, por intermédio do Instituto Nacional de Colonização e Reforma Agrária (INCRA), ainda na década de 70 , com a criação dos primeiros projetos de assentamentos. Entretanto, a produção familiar rural ainda continuava com imensas dificuldades de reprodução ${ }^{5}$, tendo em vista os problemas decorrentes de infraestrutura precária, disponibilidade de crédito inadequado e insuficiente, falta de assistência técnica etc.

Dessa forma, na década de 1990 novos modelos de assentamento são criados para encaminhar as questões não resolvidas pelos assentamentos anteriores. Em 1993, a Prefeitura Municipal de Rio Branco (PMRB) implantou os primeiros Polos Agroflorestais no município, localizados na região conhecida como Cinturão Verde, baseado na prerrogativa do desenvolvimento sustentável através do uso racional dos recursos naturais. Assim, tentavam conter o êxodo rural e assentar famílias de antigos seringueiros e agricultores, que viviam em áreas de risco ou periferias da cidade (SOUZA, 2008).

Por outro lado, alguns estudos constataram que a distribuição de terras não é suficiente para superar as condições de pobreza, uma vez que os agricultores enfrentam um conjunto de restrições para acesso aos mercados relevantes de insumos e serviços, ou seja, a viabilidade da produção familiar rural está além da reforma agrária. O desenvolvimento desse setor fundamental para a economia depende das condições básicas, como a infraestrutura adequada, acesso à tecnologia, acesso a mercados dinâmicos, a disponibilidade de crédito adequado aos padrões desse público (BUAINAIN et al., 1999; SILVEIRA et al., 2000 apud SOUZA FILHO et al., 2011).

Assim, na tentativa de viabilizar a agricultura familiar, o Governo Federal cria também na década de 1990 o Programa Nacional de Fortalecimento da Agricultura Familiar (PRONAF), que proporciona financiamentos destinados aos investimentos e manutenção das propriedades rurais. Os recursos são utilizados essencialmente em investimentos para a aquisição de insumos, matrizes leiteiras e equipamentos. O principal objetivo do programa é fortalecer o agricultor familiar do ponto de vista econômico para que gere renda suficiente para sua manutenção (GAZOLLA; SCHNEIDER, 2013).

Dando continuidade ao processo de fortalecimento da agricultura familiar, em 2003, é instituído o Programa de Aquisição de Alimentos (PAA) pelo Governo Federal, como parte da estratégia do Programa Fome Zero, na perspectiva de articular um plano de geração de renda para o público do PRONAF, através de mecanismos de comercialização nos locais de origem desses produtores, especialmente aqueles que apresentam baixo volume de produção e que ainda encontram dificuldades para agregar valor, assim, colaboram no enfrentamento da insegurança alimentar e pobreza no Brasil (REDESAN, 2010 apud SANTOS; SOARES; BENAVIDES, 2015)

Diante desse debate, surge o seguinte questionamento: os Polos Agroflorestais que formam o Cinturão Verde, considerados como novos modelos de assentamento de reforma

\footnotetext{
5 Tais entraves foram constados nos últimos 20 anos pelo Projeto de Pesquisa Análise Socioeconômica de Sistemas Básicos de Produção Familiar Rural do Estado do Acre (ASPF).
} 
agrária, implementados pela Prefeitura Municipal de Rio Branco são adequados para erradicar a pobreza e melhorar a distribuição de renda das famílias assentadas?

O presente trabalho tem por objetivo analisar a evolução da distribuição de renda em um período de dez anos entre as famílias assentadas no Cinturão de Verde do município de Rio Branco, considerando os períodos 2005/2006 e 2015/2016. Especificamente, busca-se identificar proporção das classes de renda na região, o valor de produção gerado e as condições do uso da terra.

A hipótese adotada neste trabalho é que a política de criação dos Polos Agroflorestais é fundamental para o fortalecimento da produção familiar rural, bem como contribui para o desenvolvimento dessa região, garantindo a erradicação da pobreza e melhoria da distribuição de renda.

Para chegar aos resultados obtidos, utiliza-se metodologia específica e adequada a este tipo de estudo a partir de indicadores e índices que permitem identificar a desempenho econômico das Unidades Produtivas Familiares (UPFs). Tal metodologia foi desenvolvida e consolidada nos últimos 20 anos pelo Projeto ASPF, vinculado ao Centro de Ciências Jurídicas e Sociais Aplicadas (CCJSA), da Universidade Federal do Acre (UFAC). Além disso, utilizam-se também indicadores e índices de distribuição de renda e pobreza.

O Zoneamento Econômico, Ambiental, Social e Cultural (ZEAS) de Rio Branco-AC realizou estudos no período de 2005/2006 que contemplou a zona rural do município, a qual está localizada os Polos Agroflorestais e gerou um banco de dados que permitiram a realização de novos estudos. Assim, Maciel, Campos e Souza (2010) verificaram em seus estudos um enfraquecimento da produção do autoconsumo pelas famílias, apontando uma maior dependência de aquisição de bens e serviços no mercado.

Portanto, diante desse banco de dados e resultados obtidos em período anterior, permite-se ao presente trabalho realizar uma comparação para verificar a evolução do desempenho econômico das famílias em espaço temporal de dez anos.

Entretanto, ainda há poucos estudos realizados sobre essa temática no Estado do Acre, a presente pesquisa servirá para mostrar a realidade socioeconômica e ambiental do Cinturão Verde ao poder público e também a própria comunidade para que, assim, sejam elaboradas políticas públicas adequadas que viabilizem a produção familiar rural na região e auxiliar no processo de desenvolvimento regional do Estado. 


\title{
AGRICULTURA FAMILIAR, DESENVOLVIMENTO E POBREZA RURAL
}

\author{
AGRICULTURA FAMILIAR E REFORMA AGRÁRIA
}

A necessidade de proporcionar a geração de trabalho e renda através de métodos produtivos acessíveis à agricultura familiar indica-se como uma forma de amenizar a pobreza e a desigualdade rural (DAMASCENO; KHAN; LIMA, 2011).

De acordo com Wanderley (2001), a caracterização da agricultura familiar é observada pelo trabalho assumido nas unidades produtivas pelos membros da família, além de ser a proprietária dos meios de produção. Assim, as técnicas de produção utilizadas no processo produtivo são determinadas pela família através de seus conhecimentos tradicionais.

Wanderley (2003), em um trabalho posterior, avança nessa discussão afirmando que a agricultura familiar ou o campesinato são duas dimensões distintas e complementares. De um lado, é entendida como uma civilização ou uma cultura e, por outro lado, como uma forma social particular de organização da produção.

Pereira (2010, p. 294) apresenta a definição para esse termo através da legislação:

Atualmente, a definição oficial de agricultura familiar está determinada por legislação específica, a Lei 11.326 de 2006 - a Lei da Agricultura Familiar -, que determina este conceito para qualquer intervenção governamental voltada para esse público. De acordo com a legislação, considera-se agricultor familiar aquele produtor que pratica atividades no meio rural em área não superior a 4 módulos fiscais, utilize predominantemente mão de obra da própria família nas atividades econômicas da propriedade, tenha renda familiar predominantemente gerada por meio das atividades econômicas do próprio estabelecimento e dirija a propriedade rural com sua família.

Em outro aspecto, Denardi (2001) define as unidades produtivas familiares como empreendimentos familiares, apresentando duas características principais: a gestão das unidades é realizada pela própria família e o emprego da força de trabalho familiar, com ou sem ajuda de terceiros. Para o autor, um estabelecimento familiar também é, ao mesmo tempo, uma unidade de produção, de consumo e de reprodução social.

Por outro lado, Abramovay (1997, p. 3) afirma que agricultura familiar é:

[...] aquela em que a gestão, a propriedade e a maior parte do trabalho, vêm de indivíduos que mantêm entre si laços de sangue ou de casamento. Que esta definição não seja unânime e muitas vezes tampouco operacional. É perfeitamente compreensível, já que os diferentes setores sociais e suas representações constroem categorias científicas que servirão a certas finalidades práticas: a definição de agricultura familiar, para fins de atribuição de crédito, pode não ser exatamente a mesma daquela estabelecida com finalidades de quantificação estatística num estudo acadêmico. O importante é que estes três atributos básicos (gestão, propriedade e trabalho familiar) estão presentes em todas elas.

DRd - Desenvolvimento Regional em debate (ISSNe 2237-9029) 
Segundo Guanziroli et al. (2001, p. 6) “[...] os agricultores familiares têm vantagens na gestão da força de trabalho, particularmente relevantes em processos de produção intensivos em trabalho e que exigem tratos culturais delicados e cuidadosos, que dificilmente podem ser compensados pela firma patronal”.

Além disso, a agricultura familiar gera oportunidades de trabalho local, atenua o êxodo rural, diversifica os sistemas de produção, condicionando práticas produtivas com maior sustentabilidade - social, econômica e ambiental - e contribui para o desenvolvimento local (BUAINAIN; ROMEIRO; GUANZIROLI, 2003).

Dessa forma, a produção familiar rural, observando sua dimensão ${ }^{6}$, apresenta um papel fundamental para o desenvolvimento rural no país. Segundo Salles Filho e Souza (2002), a agricultura familiar é responsável pela produção de $70 \%$ dos alimentos consumidos pela população brasileira e respondem por cerca de $40 \%$ da produção agrícola nacional.

Entretanto, de acordo com Dombek (2006), os pequenos agricultores familiares ainda encontram dificuldades para adequar-se a novas tecnologias para inserir nos seus métodos produtivos, uma vez que essa questão requer um conhecimento técnico mais avançado, o que nem sempre a agricultura familiar tem a sua disposição. Assim, esse processo tem tendência de se tornar um estorvo, implicando em uma geração de renda insuficiente para a manutenção das famílias, que, por sua vez, o endividamento externo aumentará, sendo necessário, em alguns casos, a negociação das terras, fato que aumentará o êxodo rural.

Nessa discussão, Graziano Neto (1982, p. 91) afirma:

No Brasil, a modernização da agricultura baseia-se na introdução de capital na forma de máquinas pesadas, que desocupam trabalhadores no campo. Como o preço do capital tende a ser elevado, a política agrícola mantém artificialmente barato o capital, através do crédito rural subsidiado, possibilitando essa modernização. [...] os grandes proprietários são privilegiados, seja porque detêm mais recursos e têm maior acesso ao crédito, seja porque a escala em que devem operar as máquinas é grande, não se ajustando às pequenas propriedades.

Nesse sentido, Chayanov (1974) reconhece que o produtor familiar não tem condição de produzir todos os bens necessários para sua manutenção, implicando ter uma relação mais forte no mercado. Segundo o autor, existem determinados períodos em alguns países que inviabiliza a produção de produtos agrícolas, dada as condições climáticas, como, por exemplo, o rigoroso inverno na Rússia.

É necessário refletir sobre alternativas produtivas adequadas para transformar a economia da produção familiar rural através de políticas públicas, possibilitando que o pequeno agricultor gere renda suficiente para garantir sua reprodução social no meio rural (MOREIRA, 1997).

Para tanto, Wanderley (2003) afirma que são fundamentais ações voltadas e adequadas à produção familiar rural, para que, por exemplo, os serviços de assistência técnica não tragam ruptura com os modos tradicionais de produção, de forma que seja moldada às

${ }^{6} \mathrm{O}$ Brasil caracteriza-se por ser um país predominantemente agrícola, possuindo 5,1 milhões de estabelecimentos agropecuários, apresentando cerca de 4,5 milhões estabelecimentos familiares (IBGE, 2009).

DRd - Desenvolvimento Regional em debate (ISSNe 2237-9029) 
necessidades do agricultor familiar e não tenham dificuldade com a introdução de novas técnicas produtivas.

Na década de 70, o processo de modernização conservadora foi um claro exemplo de política que inviabilizou a produção familiar rural, uma vez que desconsiderava os principais componentes para o desenvolvimento da agricultura brasileira: as relações sociais no campo e estrutura fundiária. Além disso, “[...] desconsiderava o papel primordial da produção familiar rural no processo de desenvolvimento da sociedade, em particular na Amazônia" (MACIEL; CAMPOS; SOUZA, 2010, p. 4).

Nesse aspecto, é necessária uma mudança no direcionamento das políticas públicas no meio rural, de forma que tenha como público alvo a população que apresenta maior proporção ${ }^{7}$ e que efetivamente desenvolve-se no campo:

\begin{abstract}
A reprodução da agricultura familiar depende claramente da mudança do paradigma da modernização da agricultura, como principal política de geração de renda e desenvolvimento comunitário, para um novo paradigma do desenvolvimento rural, buscando-se um novo padrão para o meio rural, porém ajustado a cada região e realidade em que se encontram as famílias rurais (MACIEL; GOMES, 2013. p. 6).
\end{abstract}

Diante das medidas de modernização conservadora, o governo brasileiro buscou ações que viabilizassem a sobrevivência e a permanência da agricultura familiar, notadamente a partir da década de 1970, através da política de reforma agrária no país (MACIEL et al., 2014).

A reforma agrária trata-se de um conjunto de medidas que tem como finalidade a distribuição de terra, a partir de modificações no regime de posse e uso, de forma que atenda aos princípios de justiça social e o aumento da produtividade (Estatuto da Terra, Lei 4.504, de 30 de novembro de 1964 . Art. $1 \S 1^{\circ}$ ).

No cenário mundial, a questão agrária começou a ser discutida efetivamente com aspecto político a partir do início do século 20, ensejado pelo debate no interior do partido socialdemocrata alemão sobre como reagir à situação da época e com o futuro da pequena produção camponesa (RAMOS, 2014).

A partir dos anos de 1980, foram incorporadas duas novas dimensões - além das dimensões econômicas, produtivas e sociais no meio rural - constitutivas da questão agrária: a dimensão ambiental, que visa a preservação e recuperação dos impactos ambientais, e a dimensão de produzir agro combustível, que permite ao setor agropecuário desempenhar essa função (idem, 2014).

De acordo com Guanziroli et al. (2001, p. 189):

A reforma agrária continua sendo um instrumento legítimo para dar acesso aos trabalhadores a um bem essencial de produção, que é a terra, e com base nesta permitir o acesso a outros meios necessários, desde a infraestrutura básica até os requerimentos mais essenciais para uma condição digna de vida, ou seja, as

\footnotetext{
${ }^{7}$ Segundo Lima e Wilkinson (2002) aproximadamente 85\% das propriedades rurais no Brasil pertencem a grupos familiares, o que demonstra forte peso desse setor no meio rural, sendo o principal responsável pela produção de alimentos no país. Além disso, de acordo com Rego, Costa Filho e Braga (2003) o maior percentual de produção, emprego e renda na Amazônia provém da pequena produção familiar rural.
} 
condições para as famílias assentadas exercerem sua cidadania. Representa uma política importante de geração de empregos no meio rural.

Assim, Schneider e Cassol (2014, p. 230) identificaram que ideologias revolucionárias tornaram a produção familiar rural foco das políticas de desenvolvimento:

A crise dos modelos de desenvolvimento, lastreados tanto nas ideologias do ajuste estrutural como nas propostas de mudança revolucionária, criou espaço para que experiências bem-sucedidas de inserção social e econômica baseadas na agricultura familiar mostrassem suas potencialidades. Em relação a isso, a agricultura familiar adquiriu centralidade política tanto para organizações internacionais como para os movimentos sociais, sindicatos e cooperativas, bem como para partidos políticos, programas e políticas públicas.

No Brasil, a política pública de implantação de assentamentos tem como objetivo principal controlar e reduzir a violência dos conflitos sociais no campo, que apresentaram maior expressividade com o surgimento das Ligas Camponesas (ROSA, 2009; FERREIRA, 2013).

De acordo com Bergamasco e Norder (1996), existem cinco tipos de assentamento: i) projetos de colonização, originados e formulados durante o período militar, a partir dos anos 70, visando à ocupação das áreas devolutas e a expansão da fronteira agrícola; ii) reassentamento de populações devido a construção de usinas hidrelétricas; iii) planos estaduais de valorização de terras públicas e de regularização possessória; iv) programas de reforma agrária e v) a criação de reservas extrativistas e outras atividades de cunho ou de aproveitamento de recursos naturais renováveis.

Os projetos de assentamentos estão distribuídos em todas as regiões do território nacional. Neste cenário brasileiro, observa-se que as regiões do Nordeste $(45 \%)$ e Norte $(22 \%)$ apresentaram as maiores quantidades de projetos do país. Porém, a Região Norte possui $75 \%$ de sua área total e $42 \%$ das famílias assentadas (INCRA, 2017).

A política de assentamentos direcionada para a Região Norte tinha como objetivo "integrar para não entregar" 8 , sendo ocupado os espaços vazios. Na maioria dos projetos de assentamento, a distribuição de infraestrutura e benfeitorias não foram consideradas na distribuição espacial, encontrando elevados e investimentos ineficazes, além de extensas áreas desflorestadas para a construção de estradas (LOPES, 2009).

Embora sejam elencados uma série de problemas ocorridos nos projetos de reforma agrária, Abramovay (2005) afirma que a distribuição de terras é um meio de ação contra a pobreza. Ela se fundamenta através do clamor de justiça e, além disso, se sustenta através da questão de sobrevivência econômica das famílias: unidades produtivas ao alcance das capacidades de trabalho de uma família podem afirmar-se economicamente e ser, portanto, um fator de geração sustentável de renda. É claro que para isso são necessárias condições de acesso a mercados dinâmicos, a crédito, a informações, a educação e a tecnologias.

Nesse sentido, diante das necessidades não atendidas pelos assentamentos tradicionais, foram implementadas novas modalidades de assentamentos na Amazônia. Assim, os Polos Agroflorestais surgiram com a proposta de garantir as famílias assentadas a responsabilidade

\footnotetext{
${ }^{8}$ Discurso nacionalista feito pelo presidente Castelo Branco em 1966, referindo-se a políticas de ocupação da região Amazônica contra a "internacionalização".
} 
pela preservação ambiental, a autossuficiência econômica e a reprodução social (MACIEL; CAMPOS; SOUZA, 2010).

De acordo com Souza (2008), no Estado do Acre, os primeiros Polos Agroflorestais foram implementados pelo governo municipal da capital acreana, Rio Branco, como uma política de fixação da produção familiar rural no campo, a partir de 1993, com base nos pressupostos do desenvolvimento sustentável desenvolvidos pela Comissão Mundial sobre Meio Ambiente e Desenvolvimento (CMMAD), em 1987, tendo como objetivo assentar famílias de seringueiros e agricultores que viviam nas periferias das cidades, sem as condições básicas de sobrevivência.

\section{DESENVOLVIMENTO RURAL}

Definir o termo desenvolvimento ainda é uma questão muito debatida entre os economistas, uma vez que existem vários extremos e, por isso, devem ser evitados. Essa definição não pode estar relacionada a crença, mito ou manipulação ideologia, como também não pode ser considerado como sinônimo de crescimento econômico (VEIGA, 2008).

Para Sen (2000), desenvolvimento é um processo de aumento das possibilidades de liberdade que as pessoas podem desfrutar. Esse termo não está relacionado a variáveis como o crescimento do PIB, aumento da renda per capita, industrialização, avanço tecnológico ou modernização como indicadores de desenvolvimento. Mas sim a expansão de liberdades, que podem ser identificados como saúde, educação e direitos civis, e que estão diretamente ligadas às cinco variáveis mencionadas anteriormente.

Dessa forma, Veiga (2001, p. 104) afirma que:

Desenvolvimento só poderia corresponder à ampliação das possibilidades de escolha: não apenas de modelos de automóvel ou canais de televisão, mas, sobretudo das oportunidades de expansão das potencialidades humanas que dependem de fatores socioculturais, como saúde, educação, comunicação, direitos e liberdade.

Por outro lado, conforme Sachs (1986), com as mudanças nos padrões de consumo da sociedade, a concentração de riqueza, a exploração de recursos naturais de forma equivocada e a divergência entre o padrão de desenvolvimento com a realidade local ensejou a busca por um novo modelo de desenvolvimento.

De acordo com Souza (2008, p. 53), “[...] tornou-se necessário despertar, a nível mundial, os governos, a comunidade acadêmica e sociedade civil para a tomada de consciência de que a crise ambiental representava uma realidade iminente e que outros modelos de desenvolvimento precisavam ser concebidos e implementados".

Assim, em 1987, a Comissão Mundial sobre o Meio Ambiente e Desenvolvimento (CMMAD) publicou o Relatório Brundtland, definindo o termo desenvolvimento sustentável como "[...] aquele que satisfaz as necessidades da geração presente, sem comprometer a capacidade das gerações futuras satisfazerem as suas próprias necessidades" (CMMAD, 1991, p. 09). 
Nesse contexto, relacionando o desenvolvimento sustentável ao desenvolvimento rural, observa-se que o meio rural deve estar atrelado à extração de recursos naturais de forma adequada para que não cause danos maiores na área explorada. Navarro $(2001$, p. 88) define desenvolvimento rural como "[...] uma ação previamente articulada que induz (ou pretende induzir) mudanças em um determinado ambiente rural. Em consequência, o Estado nacional sempre esteve presente à frente de qualquer proposta de desenvolvimento rural, como seu agente principal".

No entanto, Assis (2006, p. 81) aponta que a ausência de conhecimento técnico e recursos adequados, a questão ambiental não é desenvolvida no meio rural de acordo com o que pressupõe a sustentabilidade:

\begin{abstract}
O desenvolvimento sustentável tem como eixo central a melhoria da qualidade de vida humana dentro dos limites da capacidade de suporte dos ecossistemas e, na sua consecução, as pessoas, ao mesmo tempo que são beneficiários, são instrumentos do processo, sendo seu envolvimento fundamental para o alcance do sucesso desejado. Isto se verifica especialmente no que se refere à questão ambiental, na medida em que as populações mais pobres, ao mesmo tempo que são as mais atingidas pela degradação ambiental, em razão do desprovimento de recursos e da falta de informação, são também agentes da degradação.
\end{abstract}

Por outro lado, no Brasil, as questões agrárias e ambientais foram agravadas na década de 1970, a partir da implementação das políticas desenvolvimentistas do Governo Militar. O desenvolvimento rural, nesse período, consistia na introdução de tecnologias na agricultura, obtenção de insumos modernos para aumento da produtividade (NAVARRO, 2001).

Com intensificação do uso máquinas na agricultura, a mão de obra humana foi substituída por técnicas produtivas e tecnologias para elevar a capacidade de produção. Assim, vários trabalhadores antes ocupados com atividades agrícolas e que tinham como principal meio de subsistência o uso da terra - extrativismo -, se viram obrigados a buscar novas alternativas para sobreviverem. Muitos migraram para os centros urbanos, provocando um "inchaço populacional". Entretanto, as cidades não apresentavam uma estrutura adequada para ofertar uma boa qualidade de vida ao grande aumento de número de habitantes, assim, ocasionando diversos problemas socioeconômicos (MACIEL; CAMPOS; SOUZA, 2010).

Por outro lado, não eram apenas as questões sociais que tornaram-se uma preocupação, mas também a questão ambiental. No Brasil a adoção de técnicas produtivas inadequadas na agricultura, sendo as mesmas adotadas nos países desenvolvidos, acarretaram diversos danos ambientais na agricultura brasileira. Segundo Graziano Neto (1982, p. 93), esta é uma concepção equivocada uma vez que as condições ambientais entre um país e outro é diversa:

[...] querer reproduzir um modelo de agricultura utilizado na Europa perto da linha do Equador é demais. E, infelizmente, é o que está se fazendo. O processo de expansão da agricultura na Amazônia é condenável sob todos os aspectos, mas principalmente pelo fato de não dispormos de uma tecnologia adequada para explorar tal região.

As políticas de modernização conservadora negligenciavam as principais características de um efetivo desenvolvimento da agricultura brasileira: a estrutura fundiária e as relações sociais no campo. Além disso, "[...] desconsiderava o papel primordial da 
produção familiar rural no processo de desenvolvimento da sociedade, em particular na Amazônia" (MACIEL; CAMPOS; SOUZA, 2010, p. 4).

Outro fator que se destaca é que na Amazônia, e em particular no Acre, as consequências sociais, econômicas e ambientais da introdução de políticas desenvolvimentistas resultaram na expulsão dos povos tradicionais pelos grandes fazendeiros - a partir da década de 70, que acabou originando a necessidade de implantação de uma política de reforma agrária que resolvesse a questão agrária, de modo que o excedente de mão de obra familiar disponível fosse utilizado, uma vez que, assim, as famílias antes expulsas do meio rural poderiam retornar às práticas produtivas (MACIEL, 2003; SOUZA, 2008).

Dessa forma, percebe-se claramente a necessidade de estudos mais amplos para a implantação de políticas adequadas à região Amazônica. Principalmente, ao se tratar de alternativas e técnicas produtivas para a produção familiar rural, de forma que desempenhem atividades com práticas mais sustentáveis (RIVERO et al., 2009).

\section{DISTRIBUIÇÃO DE RENDA E POBREZA}

Vários estudos relacionados a evolução da distribuição de renda e o mercado de trabalho no Brasil mostram como resultado que o crescimento econômico ocorrido em qualquer período não foi acompanhado por uma significativa melhoria da distribuição de renda (MATOS, 2005).

Alguns autores apontam que o problema da desigualdade de renda no Brasil é um processo histórico atrelado à formação do colonial do país, caracterizada pela concentração de terras através da Lei no 601 de 1850, conhecida como a "Lei de Terra", que garantia a venda de terras devolutas (PODELESKI, 2009).

Nas últimas décadas, os dados de concentração de renda no Brasil confirmam que existe uma forte tendência de desigualdade de renda e elevados níveis de pobreza, mostrando um país desigual que herdou essa condição histórica de uma injustiça social, a qual excluiu significativamente sua população do acesso a condições mínimas de dignidade e cidadania (BARROS et al., 2001).

No cenário internacional, o Brasil é notoriamente conhecido como um dos países
menos igualitários no que se refere à distribuição de renda, tanto que,
sistematicamente, vem ocupando as últimas colocações, considerando-se o Índice de
Gini utilizado pela Organização das Nações Unidas (ONU) para comparar as
distribuições de renda no Relatório de Desenvolvimento Humano. Os últimos dados
divulgados mostram o Brasil como o $119^{\circ}$ colocado entre 124 países analisados,
sendo que, atrás dele, se encontram somente cinco países africanos (MATOS, 2005,
p. 9).

A estrutura da distribuição de renda no Brasil, entre os anos 1977-99, se manteve estagnada. Mesmo o Índice de Gini apresentando pequenas flutuações de um ano para o outro, a intensa desigualdade de renda, que acompanhou a população brasileira ao longo dos anos, se manteve estável (BARROS et al., 2001). 
Por outro lado, de acordo com Soares (2010), nos anos 2000, o Brasil surpreendeu ao experimentar reduções significativas no índice de Gini. A razão desse resultado ainda é muito debatida e, por isso, são apontadas diversas vertentes que condicionaram essa redução, como: os programas de transferências de renda do Governo Federal; mudanças no perfil educacional da população ocupada; a relevância dos preços relativos; mudanças da estrutura demográfica e no mercado de trabalho.

A Tabela 1 confirma que realmente existe uma tendência de queda no Índice de Gini no Brasil. Vale destacar que as regiões Sul e Sudeste são caracterizadas como as regiões brasileiras mais desenvolvidas, portanto, é provável que a melhoria da distribuição de renda ocorreu através de mudanças no mercado de trabalho, pelo perfil educacional da população ocupada e pela mudança na estrutura demográfica.

Tabela 1 - Índice de Gini das Regiões do Brasil para o período de 2004 a 2014.

\begin{tabular}{lccccccccccc}
\hline \multicolumn{1}{c}{ Região } & $\mathbf{2 0 0 4}$ & $\mathbf{2 0 0 5}$ & $\mathbf{2 0 0 6}$ & $\mathbf{2 0 0 7}$ & $\mathbf{2 0 0 8}$ & $\mathbf{2 0 0 9}$ & $\mathbf{2 0 1 1}$ & $\mathbf{2 0 1 2}$ & $\mathbf{2 0 1 3}$ & $\mathbf{2 0 1 4}$ & Variação (\%)* $^{*}$ \\
\hline Brasil & 0,572 & 0,570 & 0,563 & 0,556 & 0,546 & 0,543 & 0,531 & 0,530 & 0,527 & 0,518 & $-9,52 \%$ \\
Centro-Oeste & 0,572 & 0,577 & 0,562 & 0,574 & 0,567 & 0,560 & 0,537 & 0,531 & 0,528 & 0,511 & $-10,70 \%$ \\
Norte & 0,541 & 0,530 & 0,522 & 0,535 & 0,510 & 0,522 & 0,535 & 0,513 & 0,517 & 0,505 & $-6,69 \%$ \\
Nordeste & 0,583 & 0,571 & 0,573 & 0,564 & 0,558 & 0,558 & 0,544 & 0,542 & 0,537 & 0,516 & $-11,55 \%$ \\
Sul & 0,522 & 0,515 & 0,506 & 0,505 & 0,494 & 0,491 & 0,472 & 0,468 & 0,465 & 0,456 & $-12,75 \%$ \\
Sudeste & 0,542 & 0,543 & 0,537 & 0,523 & 0,515 & 0,511 & 0,501 & 0,505 & 0,504 & 0,501 & $-7,59 \%$ \\
\hline
\end{tabular}

Fonte: IPEADATA (2017).

*Para o período 2004/2014.

A distribuição de renda no Brasil apresentou uma melhora significativa nos últimos anos, porém, ainda é considerada muito elevada ao comparar com países considerados desenvolvidos (HOFFMANN, 2009).

De acordo com Soares (2010), entre 2001 e 2006, o Brasil apresentou uma queda de 0,7 pontos percentuais ao ano no Índice de Gini. Se o país manter essa redução substancial nas duas próximas décadas poderá se igualar a países desenvolvidos no tocante a distribuição de renda, porém, alerta que haja também uma melhoria no bem-estar dos brasileiros.

Por outro lado, Silva (2010) afirma que no Brasil sempre se teve um contingente populacional à margem da sociedade, que nunca foram inseridos no trabalho formal e nem participaram de uma socialização.

Segundo Kowarick (1999, apud SILVA, 2010), a sociedade brasileira é extremamente excludente do ponto de vista econômico e social, constituindo massas de trabalhadores autônomos ou assalariados com rendimentos muito aquém que os condicionam a uma vida precária e sem garantia social.

De modo que, no Brasil, a pobreza aprofundou-se como consequência de um desenvolvimento concentrador da riqueza socialmente produzida e dos espaços territoriais, representados pelos grandes latifúndios no meio rural, e pela especulação

DRd - Desenvolvimento Regional em debate (ISSNe 2237-9029) 
imobiliária no meio urbano. Tem raízes na formação sócio histórica e econômica da sociedade brasileira (SILVA, 2010, p. 157).

Para Sen (2000), a pobreza deve ser encarada como um elemento de privação das capacidades básicas do indivíduo e afeta diretamente sobre as condições de vida das pessoas, deixando-as em patamares localmente definidos como não desejados.

De acordo com Soares (2009), a pobreza é caracterizada em unidimensional ou multidimensional. A pobreza unidimensional está relacionada a privações das necessidades básicas em decorrência ao baixo nível de renda. Assim, considera-se dois parâmetros: a linha de indigência e a linha de pobreza. A primeira está atrelada ao valor monetário mínimo para a aquisição de alimentação que tenha a quantidade energética básica ou recomendada para a sobrevivência do indivíduo. Já a segunda além de contemplar a alimentação, inclui as demais despesas como: roupa, educação, moradia, transporte e saúde, bem como considera o acesso as questões fundamentais da sociedade quanto aos direitos e obrigações no exercício da cidadania através de análise de variáveis culturais, sociais e políticas.

A pobreza multidimensional apresenta três aspectos distintos: intensidade/severidade, que diz respeito a mensuração dos níveis de pobreza; tempo/duração, atentando-se com a questão temporal da pobreza, especialmente a sua permanência; e dimensões/extensões, focando seu estudo nas diversas formas de privação na vida de um indivíduo (OLIVEIRA, 2010).

A concentração de renda e as desigualdades sociais, problemas ligados diretamente a pobreza, são também responsáveis pela maioria dos problemas econômicos, sociais e ambientais no Brasil (COSTA, 2000).

Identifica-se um consenso, tanto no campo acadêmico como entre políticos de todas
as matizes ideológicas e partidárias, que a pobreza no Brasil decorre, em grande
parte, de um quadro de extrema desigualdade, marcado por profunda concentração
de renda. Essa situação coloca o Brasil entre os países de maior concentração de
renda no mundo, apesar do declínio nesse índice que se vem registrando (SILVA,
2010 , p. 156).

Junto aos problemas decorrentes da pobreza, em relação as comunidades rurais na Amazônia, a distância e dificuldade de acesso, a baixa participação ou inexistência de acesso a serviços sociais básicos deixam as comunidades rurais mais vulneráveis (SOUZA, 2008).

Para tanto, a região Norte brasileira constitui uma economia caracterizada por muitas fragilidades, entre elas, o baixo nível de industrialização e inovação tecnológica, infraestrutura deficitária e a grandes dificuldades de angariar investimentos (NOGUEIRA; SILVA, 2015).

Assim, nos últimos anos, as regiões Norte e Nordeste do Brasil se tornaram focos das políticas de transferências de renda do Governo Federal e apresentaram resultados significativos nos índices de distribuição de renda. Entretanto, na Amazônia é fundamental pensar em políticas de distribuição de renda que efetivamente irão gerar desenvolvimento regional a partir de produção, comercialização e consumo de produtos regionais. 


\section{METODOLOGIA}

O presente trabalho teve como objetivo realizar um estudo sobre a distribuição de renda e pobreza rural na Amazônia, em particular na área denominada de Cinturão Verde, onde estão localizados os Polos Agroflorestais do município de Rio Branco-AC, e é resultado do relatório técnico intitulado "Diagnóstico Social, Produtivo e Econômico do Cinturão Verde de Rio Branco", financiado com recursos da Secretaria Municipal de Floresta e Reforma Agrária (SAFRA).

A pesquisa seguiu a metodologia mais adequada para o levantamento de dados primários e secundários, através de aplicação de questionários específicos junto aos produtores, sendo as entrevistas coletivas e/ou individuais, para extrair as informações quantitativas e qualitativas da região estudada. Para os levantamentos e análise dos dados primários, foi utilizada a metodologia do Projeto ASPF (Análise Socioeconômica de Sistemas Básicos da Produção Familiar Rural no Estado do Acre), a qual a avaliação é feita por meio de indicadores econômicos, sociais e produtivos.

O Projeto ASPF foi criado em novembro de 1996, tendo como objeto de pesquisa as áreas representativas da realidade socioeconômica rural do Estado do Acre. Atualmente, o projeto é vinculado pelo Centro de Ciências Jurídicas e Sociais Aplicadas (CCJSA) da Universidade Federal do Acre (UFAC) e desenvolveu uma metodologia adequada e específica para a produção familiar rural, em particular na Amazônia, consolidando-se nos últimos 20 anos.

Destaca-se que o Projeto ASPF realizou dois levantamentos completos no Estado do Acre, considerando os períodos de 1996/1997 e 2005/2006, sendo que neste último período desenvolveu-se trabalho específico na zona rural de Rio Branco-AC, através da execução do Zoneamento Econômico, Ambiental, Social e Cultural de Rio Branco (ZEAS), que contemplou o Cinturão Verde, aonde se encontram os Polos Agroflorestais, com levantamentos censitários.

Assim, os resultados do período anterior permitem realizar uma comparação com a presente pesquisa e verificar a evolução dos indicadores e índices em um espaço temporal de dez anos, identificando como está a situação atual das famílias residentes do Cinturão Verde.

\section{ÁREA DE ESTUDO}

O município de Rio Branco é a capital do Estado do Acre e está localizado na mesorregião do Vale do Acre, criado em 1882. Segundo o IBGE (2015), a população estimada em 2015 foi de 370.550 mil habitantes. O município possui uma área territorial de $8.835,541 \mathrm{~km}^{2}$, cuja densidade demográfica é $38,03 \mathrm{hab} / \mathrm{km}^{2}$. O IDHM do município, em 2010, foi de 0,727. O PIB per capita de R \$ 18.946,97, em 2013, demonstrando uma elevada concentração de renda ao observar que a renda média nominal mensal na zona urbana foi de $\mathrm{R} \$ 2.770,79$ e na zona rural, média mensal, de $\mathrm{R} \$ 1.357,02$. 
Segundo a Associação dos Municípios do Acre (AMAC) ${ }^{9}$, Rio Branco apresenta um grande número de bairros devido ao intenso fluxo migratório ocorrido nos anos de 1970. Esse processo fez a cidade concentrar metade da população de todo o Estado. Sua economia está baseada no extrativismo vegetal, agricultura, pecuária e comércio. O município tem a quinta maior extensão territorial do Estado, limita-se ao norte, com os municípios de Bujari e Porto Acre; ao sul com os municípios de Xapuri e Capixaba; a leste, com o município de Senador Guiomard e a oeste, com o município de Sena Madureira. O acesso ao município é feito por meio rodoviário através da BR-364, fluvial através do Rio Acre e aéreo através do aeroporto internacional.

\section{AMOSTRA}

As entrevistas foram realizadas mediante reuniões com as comunidades envolvidas no levantamento, além de entrevistas individuais nas propriedades dos principais produtores da região, orientadas pelas lideranças locais. Assim, as previsões iniciais foram ajustadas tanto nas reuniões quanto em conversas com os líderes locais para melhor adequação dos levantamentos.

As pesquisas com os produtores da região de estudo foram efetuadas nos meses de março e abril de 2016. A equipe envolvida no diagnóstico é composta por profissionais, graduandos, técnicos e lideranças das próprias comunidades envolvidas. Destaca-se que o envolvimento dos técnicos/lideranças das comunidades foi primordial para a obtenção de informações satisfatórias.

Na Tabela 2 são apresentadas a população e a amostra pesquisadas no Cinturão Verde de Rio Branco-AC.

Tabela 2 - População e Amostra pesquisadas no Cinturão Verde de Rio Branco, Acre - 2016.

\begin{tabular}{lccc}
\hline \multicolumn{1}{c}{ Local } & Famílias Assentadas (1) & Amostra (2) & (2/1) \% \\
\hline Polo Agroflorestal 9 Irmãos & 9 & 7 & $78 \%$ \\
Polo Agroflorestal Custódio Freire & 20 & 10 & $50 \%$ \\
Polo Agroflorestal Hélio Pimenta & 34 & 17 & $50 \%$ \\
Polo Agroflorestal Benfica & 43 & 13 & $30 \%$ \\
Polo Agroflorestal Wilson Pinheiro & 40 & 18 & $45 \%$ \\
Polo Agroflorestal Dom Joaquim & 17 & 7 & $41 \%$ \\
Polo Agroflorestal Geraldo Fleming & 60 & 24 & $40 \%$ \\
Polo Barro Vermelho & - & 13 & - \\
Polo Catuaba & 73 & 14 & $19 \%$ \\
Polo Quixadá & - & 23 & - \\
Total & $\mathbf{2 9 6}$ & $\mathbf{1 4 6}$ & $\mathbf{4 9 \%}$ \\
\hline
\end{tabular}

Fonte: ASPF (2017).

${ }^{9}$ AMAC, http://www.amac-acre.com.br/site/?page id=677 (2016) 


\section{INDICADORES DE AVALIAÇÃO ECONÔMICA}

Os principais indicadores econômicos são sucintamente descritos a seguir ${ }^{10}$ :

1) Resultado Bruto

-Renda Bruta (RB) - indicador de escala de produção. Definida pela seguinte fórmula:

$$
R B=Q m \cdot p p
$$

Sendo,

$\mathrm{Qm}=$ Quantidade do Produto Destinada ao Mercado;

$\mathrm{Pp}=$ Preço Unitário ao Produtor.

-Renda Bruta Total (RBT) - somatório da RB com as rendas das transferências governamentais (bolsa família etc.) e do assalariamento fora da unidade produtiva. Definida pela seguinte fórmula:

$$
R B T=R B+R T+R A
$$

Sendo:

$\mathrm{RBT}=$ Renda Bruta Total;

$\mathrm{RB}=$ Renda Bruta;

$\mathrm{RT}=$ Renda das Transferências Monetárias;

$\mathrm{RA}=$ Renda de Assalariamento.

2) Resultados Líquidos

Margem Bruta Familiar (MBF) - valor monetário disponível para a família. É dada pela seguinte fórmula:

$$
M B F=R B-(C V-C f t f)
$$

Sendo:

$\mathrm{RB}=$ Renda Bruta;

$\mathrm{CV}=$ Custos Variáveis;

$\mathrm{Cftf}=$ Custo Real da Força de Trabalho Familiar.

${ }^{10}$ A metodologia completa está disponível em: http://aspf.wordpress.com/category/metodologia/ 


\section{3) Linha de Dependência do Mercado (LDM)}

Definem-se como linha de dependência do mercado os valores medianos gastos com bens e serviços de consumo no mercado, adicionados das compras relacionadas à reposição do capital fixo (máquinas, equipamentos, ferramentas, benfeitorias etc.) disponível para a manutenção dos meios de produção existentes.

4) Índice de Gini

O Índice de Gini é uma medida de concentração ou desigualdade utilizada na análise da distribuição de renda e pode ser utilizado para medir o grau de concentração de qualquer distribuição estatística.

Geometricamente o Índice de Gini pode ser definido pela seguinte fórmula:

$$
G=\left|1-\sum_{k=1}^{k=n-1}\left(X_{k+1}-X_{k}\right)\left(Y_{k+1}+Y_{k}\right)\right|
$$

sendo,

$\mathrm{G}=$ coeficiente de Gini

$\mathrm{X}=$ proporção acumulada da variável "população"

$\mathrm{Y}=$ proporção acumulada da variável "rendimento"

5) Razão 10\%+ / 50\% - ou Razão de Kuznets

Criada por Simon Kuznets (1955), expressa a forma geométrica da relação entre crescimento e desigualdade. Em suma é uma forma de mensurar a desigualdade existente na distribuição de renda dos indivíduos mais ricos com a renda dos indivíduos mais pobres. Compara-se a renda de $10 \%$ dos indivíduos mais ricos relativamente a renda de $50 \%$ dos indivíduos mais pobres. Destaca-se que quanto maior for esta razão maior é a distância das rendas entre os mais ricos e os mais pobres.

\section{6) Linha de Pobreza}

Entre os métodos que definem a linha de indigência ou pobreza definida pela renda destacam-se aqueles que se utilizam da proporção do salário mínimo $(\mathrm{SM})^{11}$. Este método é bastante utilizado, uma vez que, em tese, o salário mínimo deveria suprir as necessidades básicas, não só da alimentação mas também da moradia, vestuário, etc. Os valores comumente utilizados como linha de pobreza está entre $1 / 4$ e $1 / 2$ do salário mínimo, como em Hoffmann (2002).

\footnotetext{
${ }^{11}$ No presente trabalho adotou-se o salário mínimo instituído em janeiro do ano de 2016, sendo o valor de $\mathrm{R} \$ 880,00$.
} 
No presente trabalho foram estratificadas cinco classes sociais, sendo a classe A composta por produtores que detém uma renda acima de quatro salários mínimos, a classe $\mathrm{B}$ de dois a quatro salários mínimos, a classe $\mathrm{C}$ de $1 / 2$ a dois salários mínimos, a classe $\mathrm{D}$ que ganham até $1 / 2$ salário mínimo e, por fim, a classe $\mathrm{E}$ famílias com renda inferior a $1 / 4$ de salário mínimo.

Tabela 3 - Classificação da faixa de renda, valores conforme o salário mínimo.

\begin{tabular}{cc}
\hline Classe & Faixas de Renda (SM) \\
\hline A & $\mathrm{RB}>4 \mathrm{SM} / \mathrm{mês} ;$ \\
$\mathrm{B}$ & $2 \mathrm{SM} / \mathrm{mês}<\mathrm{RB}<4 \mathrm{SM} / \mathrm{mês} ;$ \\
$\mathrm{C}$ & $1 / 2 \mathrm{SM} / \mathrm{mês}<\mathrm{RB}<2 \mathrm{SM} / \mathrm{mês} ;$ \\
$\mathrm{D}-$ Pobreza & $1 / 4 \mathrm{SM} / \mathrm{mês}<\mathrm{RB}<1 / 2 \mathrm{SM} / \mathrm{mês} ;$ \\
E - Extrema Pobreza & $\mathrm{RB}<1 / 4 \mathrm{SM} / \mathrm{mês} ;$ \\
\hline
\end{tabular}

Fonte: ASPF (2017).

\section{RESULTADOS E DISCUSSÕES}

Um primeiro aspecto importante é a discussão em torno do uso da terra pelas famílias. No Gráfico 1, percebe-se que o tamanho das áreas utilizadas para os diversos fins produtivos é considerado pequeno - com área mediana de 4,5 hectares para todo o Cinturão Verde - para os padrões de assentamentos rurais mais antigos - que giram entre 50 a 100 hectares -, mas adequados de acordo com o planejamento sob a ótica dos Polos Agroflorestais, inicialmente implantados no município de Rio Branco-AC.

Gráfico 1 - Área (ha) mediana das Unidades Produtivas Familiares pesquisadas no Cinturão Verde de Rio Branco, Acre - 2016.

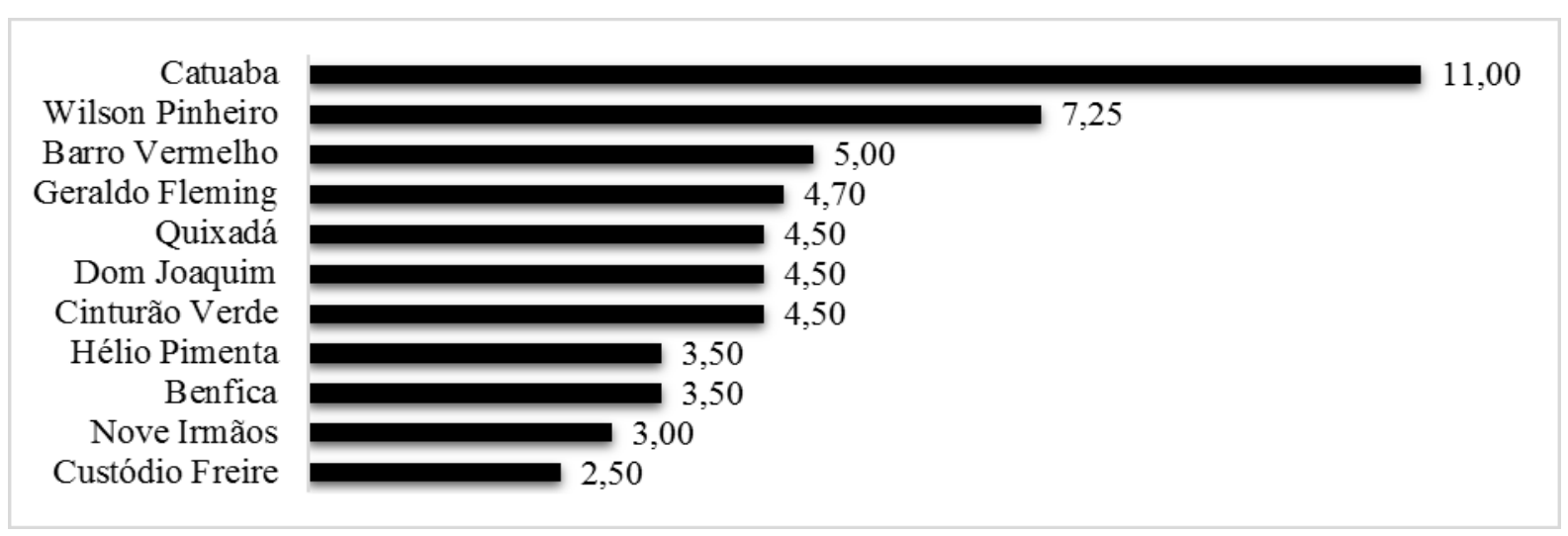

Fonte: ASPF (2017).

Essa adequação do tamanho das áreas está em consonância com os tipos de atividades previstas, que são intensivas na utilização do espaço e da mão de obra familiar, como a 
produção de hortaliças e sistemas agroflorestais (SAFs), em detrimento das atividades extensivas, tradicionalmente trabalhadas nas áreas rurais da região, como a produção de gado bovino. Cabe destacar que os Polos Agroflorestais foram implantados justamente em áreas de pastagens degradadas, praticamente sem florestas nativas, com a missão de recuperação do solo a partir de novas práticas agrícolas, como os SAFs, além da pecuária, com a criação de pequenos animais.

Conforme o Gráfico 2, observa-se que os Polos Agroflorestais vêm cumprindo sua missão ao longo dos últimos dez anos. Pois, cerca de $20 \%$ dos sistemas agroflorestais trabalhados em 2005/2006 foram considerados como Floresta e Capoeira, dada sua maturidade, no período atual, apesar do aumento das pastagens para $5 \%$ da área total. Entretanto, torna-se preocupante a expressiva queda das atividades de SAFs, em torno de 93\%, para outras atividades notadamente de monocultivo, como os plantios de culturas perenes, como é o caso da banana, e dos roçados, no caso da mandioca.

Gráfico 2 - Evolução Percentual da área total, por tipo de uso da terra, das Unidades Produtivas Familiares pesquisadas nos Polos Agroflorestais de Rio Branco, Acre - 2005/2006 e 2015/2016.

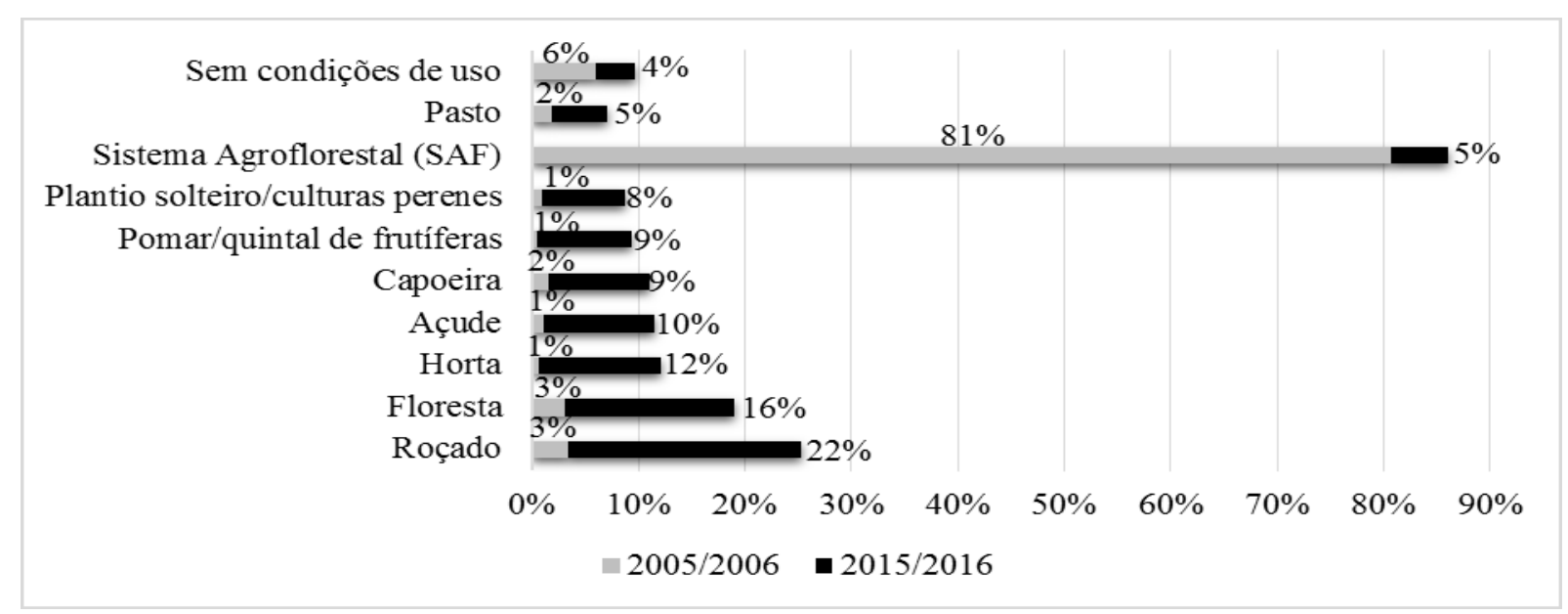

Fonte: ZEAS (2008); ASPF (2017).

Por outro lado, ressalta-se a acentuação da diversificação produtiva nos Polos Agroflorestais, nos últimos dez anos, em particular da produção de hortaliças, demonstrando maior equilíbrio no uso da terra, característica essencial da agricultura familiar.

Os principais produtos oriundos do uso da terra pelas famílias do Cinturão Verde de Rio Branco-AC e comercializados no mercado estão sintetizados na Tabela 4. Um primeiro aspecto a observar é que cerca de $70 \%$ dos produtores vendem algum tipo de banana, com produção vendida estimada em torno de $452.000 \mathrm{~kg}$; quase $80 \%$ comercializam mais de mil toneladas de mandioca e seus derivados (farinha e goma); e pelo menos $65 \%$ das famílias vendem hortaliças no mercado, com mais de 4 milhões de maços comercializados. 
Tabela 4 - Percentual de famílias por tipo de produto e estimativas das quantidades média e total vendidas pelas famílias do Cinturão Verde de Rio Branco, Acre, 2015/2016.

\begin{tabular}{|c|c|c|c|}
\hline \multirow{2}{*}{ Grupo/Produto } & \multirow{2}{*}{ \% Famílias Produtoras } & \multicolumn{2}{|c|}{ Quantidade } \\
\hline & & Média & Total \\
\hline \multicolumn{4}{|l|}{ Frutíferas } \\
\hline Banana $(\mathrm{Kg})$ & & & $451.973,82$ \\
\hline Banana Maçã (Kg) & $19 \%$ & $2.458,25$ & $121.161,42$ \\
\hline Banana Prata $(\mathrm{Kg})$ & $45 \%$ & $2.621,70$ & $304.584,32$ \\
\hline Banana Comprida $(\mathrm{Kg})$ & $8 \%$ & $1.354,55$ & $26.228,08$ \\
\hline Melancia (Unidade) & $3 \%$ & $1.839,00$ & $16.185,72$ \\
\hline Laranja $(\mathrm{Kg})$ & $18 \%$ & $1.464,89$ & $69.622,36$ \\
\hline Limão (Kg) & $28 \%$ & $1.223,41$ & $88.295,34$ \\
\hline \multicolumn{4}{|l|}{ Tuberosas } \\
\hline Macaxeira (Kg) & $51 \%$ & $5.718,61$ & $754.974,47$ \\
\hline Farinha $(\mathrm{Kg})$ & $7 \%$ & 876,00 & $15.420,00$ \\
\hline Goma (Kg) & $21 \%$ & $5.490,07$ & $289.920,64$ \\
\hline \multicolumn{4}{|l|}{ Hortaliças } \\
\hline Alface (Maço) & $45 \%$ & $3.255,11$ & $378.171,98$ \\
\hline Pimenta de cheiro $(\mathrm{Kg})$ & $28 \%$ & 352,12 & $25.413,08$ \\
\hline Couve (Maço) & $54 \%$ & $10.869,74$ & $1.511 .564,16$ \\
\hline Cheiro-verde (Maço) & $65 \%$ & $12.808,49$ & $2.141 .913,69$ \\
\hline
\end{tabular}

Fonte: ASPF (2017).

Do ponto de vista econômico, é necessário entender quais produtos são procurados pelo mercado, identificando a quantidade absorvida e o preço pago para se estudar o processo de geração de renda, da produção à comercialização no mercado. De acordo com a Tabela 5, estima-se que entre as famílias pesquisadas do Cinturão Verde, foram gerados de renda bruta na região cerca de 10,2 milhões de reais, no ano agrícola de 2015/2016, com destaque para a comercialização das hortaliças, com quase $30 \%$ do total - principalmente couve $(10 \%)$ e cheiro-verde (12\%) -, e da mandioca e goma, responsáveis por $11,5 \%$ e 10,5\%, respectivamente, do total da renda bruta gerada.

Um aspecto importante a ser ressaltado na demanda efetiva responsável pela magnitude da renda bruta gerada foi o papel decisivo do Programa de Aquisição de Alimentos, cujas compras são efetuadas pelos governos estaduais e prefeituras municipais, além do governo federal pela Companhia Nacional de Abastecimento (CONAB). Percebeu-se nas coletas de informações a importância desse programa tanto na quantidade quanto nos preços relacionados aos produtos comercializados, funcionando com uma espécie de regulador do mercado. 
Tabela 5 - Renda Bruta gerada entre as famílias do Cinturão Verde de Rio Branco, Acre - Ano Agrícola $2015 / 2016$.

\begin{tabular}{|c|c|c|c|c|c|}
\hline \multirow[b]{2}{*}{ Grupo/Produto } & \multirow[b]{2}{*}{ Preço Médio (R\$) } & \multicolumn{3}{|c|}{ Renda (R\$) } & \multirow[b]{2}{*}{$\%$ Total } \\
\hline & & $\begin{array}{c}\text { Média } \\
\text { Anual }\end{array}$ & $\begin{array}{l}\text { Média } \\
\text { Mensal }\end{array}$ & Total & \\
\hline Frutíferas & & $5.066,74$ & 422,23 & $1.302 .151,88$ & $12,75 \%$ \\
\hline Banana (Kg) & & & & $850.942,88$ & $8,33 \%$ \\
\hline Banana Maçã (Kg) & 1,69 & $4.154,44$ & 346,20 & $204.762,80$ & $2,00 \%$ \\
\hline Banana Prata $(\mathrm{Kg})$ & 1,85 & $4.845,71$ & 403,81 & $562.965,54$ & $5,51 \%$ \\
\hline Banana Comprida (Kg) & 3,17 & $4.297,60$ & 358,13 & $83.214,55$ & $0,81 \%$ \\
\hline Melancia (Unidade) & 7,60 & $13.976,40$ & $1.164,70$ & $123.011,47$ & $1,20 \%$ \\
\hline Laranja $(\mathrm{Kg})$ & 2,42 & $3.542,86$ & 295,24 & $168.382,96$ & $1,65 \%$ \\
\hline Limão (Kg) & 1,81 & $2.214,38$ & 184,53 & $159.814,57$ & $1,56 \%$ \\
\hline Tuberosas & & $8.895,43$ & 741,29 & 2.286.124,47 & $22,38 \%$ \\
\hline Mandioca $(\mathrm{Kg})$ & 1,56 & $8.917,22$ & 743,10 & $1.177 .256,85$ & $11,53 \%$ \\
\hline Farinha de Mandioca $(\mathrm{Kg})$ & 3,35 & $2.934,60$ & 244,55 & $51.657,00$ & $0,51 \%$ \\
\hline Goma de Mandioca (Kg) & 3,65 & $20.019,81$ & $1.668,32$ & $1.057 .210,62$ & $10,35 \%$ \\
\hline Hortaliças & & $11.805,51$ & 983,79 & 3.034.015,00 & $29,71 \%$ \\
\hline Alface (Maço) & 1,70 & $5.540,19$ & 461,68 & $643.648,71$ & $6,30 \%$ \\
\hline Pimenta de cheiro $(\mathrm{Kg})$ & 3,95 & $1.391,31$ & 115,94 & $100.412,64$ & $0,98 \%$ \\
\hline Couve (Maço) & 0,68 & $7.411,45$ & 617,62 & $1.030 .648,09$ & $10,09 \%$ \\
\hline Cheiro-verde (Maço) & 0,59 & $7.530,56$ & 627,55 & $1.259 .305,56$ & $12,33 \%$ \\
\hline Outras culturas & & $10.631,88$ & $\mathbf{8 8 5 , 9 9}$ & 2.152.227,09 & $21,07 \%$ \\
\hline Criações & & $5.596,81$ & 466,40 & $1.438 .380,81$ & $14,08 \%$ \\
\hline Galinha/Pato (Aves) & 27,21 & $3.073,90$ & 256,16 & $389.591,27$ & $3,81 \%$ \\
\hline Peixes & 30,40 & $35.845,40$ & $2.987,12$ & $1.009 .563,59$ & $9,89 \%$ \\
\hline Outras criações & & $5.603,71$ & 466,98 & $39.225,95$ & $0,38 \%$ \\
\hline Total & & $39.738,91$ & $3.311,58$ & $10.212 .899,25$ & $100 \%$ \\
\hline
\end{tabular}

Fonte: ASPF (2017).

Depois de identificar como ocorre a geração de renda, é possível verificar como está distribuída na região. O Gráfico 3 demonstra a grande desigualdade de renda nas áreas pesquisadas. As rendas recebidas em valores mensais variam de aproximadamente $\mathrm{R} \$ 123,00$ a $\mathrm{R} \$ 12.600,00$, com renda bruta mediana em torno de $\mathrm{R} \$ 1.970,00 /$ mês. Isto significa que metade das famílias recebe abaixo desse valor e metade recebe acima do valor mediano. Ressalta-se que esse valor mediano representa cerca de 2,2 salários mínimos (SM) mensais.

DRd - Desenvolvimento Regional em debate (ISSNe 2237-9029) 
Gráfico 3 - Renda Bruta mensal (R \$mês) gerada entre produtores do Cinturão Verde de Rio Branco, Acre $2015 / 2016$.

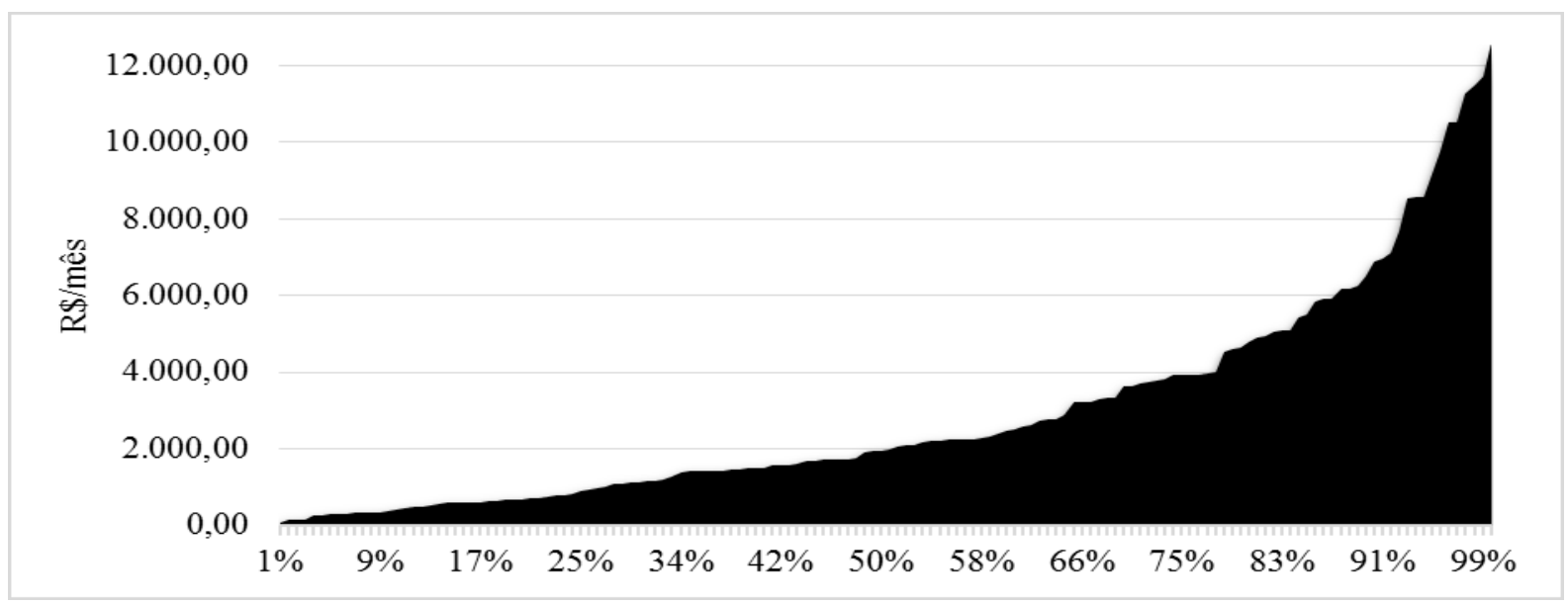

Fonte: ASPF (2017).

$\mathrm{Na}$ Tabela 6 são apresentados alguns índices de desigualdade de renda na região do Cinturão Verde de Rio Branco-AC. O Índice de Gini da região acompanha o alto padrão brasileiro de concentração de renda, com 0,48 , sendo que o ideal seria um índice mais próximo de zero. Entre as áreas estudadas se percebe que nos Polos Agroflorestais Catuaba e Barro Vermelho a concentração de renda é muito elevada, com Gini de 0,49 , e os $10 \%$ das famílias mais ricas ganham 1,35 e 1,43 vezes, respectivamente, o que ganham metade das famílias restantes. Por outro lado, várias áreas têm distribuição de renda mais equitativa, com Gini entre 0,30 e 0,40, destacando-se o Polo Dom Joaquim, com Gini de 0,27 - marca semelhante aos países desenvolvidos.

Tabela 6 - Indicadores de desigualdade de renda entre as famílias do Cinturão Verde de Rio Branco, Acre $2015 / 2016$.

\begin{tabular}{lcccc}
\hline \multirow{2}{*}{ Áreas Pesquisadas } & \multicolumn{4}{c}{ Indicadores de Desigualdade de Renda } \\
\cline { 2 - 5 } & Índice de Gini & \% renda 10+(A) & \% renda 50- (B) & A/B \\
\hline Catuaba & 0,49 & $19 \%$ & $14 \%$ & 1,35 \\
Cinturão Verde & $\mathbf{0 , 4 8}$ & $\mathbf{2 2 \%}$ & $\mathbf{1 7 \%}$ & $\mathbf{1 , 3 2}$ \\
Barro Vermelho & 0,49 & $29 \%$ & $20 \%$ & 1,43 \\
Geraldo Fleming & 0,50 & $21 \%$ & $15 \%$ & 1,44 \\
Custódio Freire & 0,43 & $15 \%$ & $15 \%$ & 1,02 \\
Hélio Pimenta & 0,48 & $23 \%$ & $14 \%$ & 1,69 \\
Quixadá & 0,36 & $15 \%$ & $23 \%$ & 0,65 \\
Wilson Pinheiro & 0,36 & $24 \%$ & $28 \%$ & 0,87 \\
Nove Irmãos & 0,33 & $18 \%$ & $18 \%$ & 0,98 \\
Benfica & 0,32 & $20 \%$ & $28 \%$ & 0,69 \\
Dom Joaquim & 0,27 & $21 \%$ & $41 \%$ & 0,50 \\
\hline
\end{tabular}

Fonte: ASPF (2017).

Mais ainda relevante é notar a evolução da distribuição de renda entre os Polos Agroflorestais, nos últimos dez anos, conforme a Tabela 7. Entre o último levantamento feito na região, realizado pela Prefeitura de Rio Branco-AC (através do ZEAS), no período de 
2005/2006, praticamente em todos os Polos tiveram melhoria na distribuição de renda entre os produtores familiares, com destaque para os Polos Benfica (-32\%) e Wilson Pinheiro (-19\%) e, claro, para a manutenção da distribuição equitativa no Dom Joaquim.

Tabela 7 - Evolução do Índice de Gini (nível de concentração de renda) entre as famílias das áreas dos Polos Agroflorestais do Cinturão Verde de Rio Branco, Acre - 2015/2016.

\begin{tabular}{lccc}
\hline \multirow{2}{*}{ Áreas Pesquisadas } & & Índice de Gini & Evolução (\%) \\
\cline { 2 - 4 } & $\mathbf{2 0 0 5 / 2 0 0 6}$ & $\mathbf{2 0 1 5 / 2 0 1 6}$ & - \\
\hline Catuaba & - & 0,49 & - \\
Barro Vermelho & - & 0,49 & $-4 \%$ \\
Geraldo Fleming & 0,52 & 0,50 & $2 \%$ \\
Custódio Freire & 0,42 & 0,43 & $-8 \%$ \\
Hélio Pimenta & 0,52 & 0,48 & - \\
Cinturão Verde & - & 0,48 & - \\
Quixadá & - & 0,36 & $-19 \%$ \\
Wilson Pinheiro & 0,45 & 0,36 & - \\
Nove Irmãos & - & 0,33 & $-32 \%$ \\
Benfica & 0,47 & 0,32 & $4 \%$ \\
Dom Joaquim & 0,26 & 0,27 & \\
\hline Fonte: ASPF & & &
\end{tabular}

Fonte: ASPF (2017).

Entretanto, não se quer dizer que o Dom Joaquim é mais desenvolvido que as outras áreas ou tem padrão de desenvolvimento das regiões ricas, mas que a distribuição é mais igualitária, mesmo se a renda for mais baixa que os demais, pois o Índice de Gini mede apenas o nível de concentração de renda e não a qualidade de vida ou nível de pobreza.

Por isso, é importante observar, ainda na Tabela 7, os índices do Polo Custódio Freire, pois apresenta alto Gini, com 0,43 , mas com a relação entre os $10 \%$ mais e os $50 \%$ mais pobres de forma diferente, ou seja, bem mais favorável aos mais pobres.

Essa relação pode ser mais bem explicada mediante o Gráfico 4, que estratifica a renda bruta gerada de acordo com a classe de rendimentos que as famílias recebem oriundas de seu processo produtivo. Pois, nota-se que além de não existirem famílias consideradas pobres não somente no Polo Geraldo Fleming, bem como no Custódio Freire e Quixadá, mais da metade das famílias dessas áreas foram enquadradas na classe $\mathrm{A}$, já que recebem valores superiores a quatro salários mínimos mensais ( $\mathrm{R} \$ 3.520,00)$. Cabe destacar ainda que a distribuição de renda mais igualitária no Dom Joaquim é observada no enquadramento de mais de $86 \%$ na classe $\mathrm{C}$, recebendo remunerações brutas entre meio a dois $\mathrm{SM} / \mathrm{mês}$. 
Gráfico 4 - Distribuição percentual das famílias, de acordo com a classe de renda, do Cinturão Verde de Rio Branco, Acre - 2015/2016.

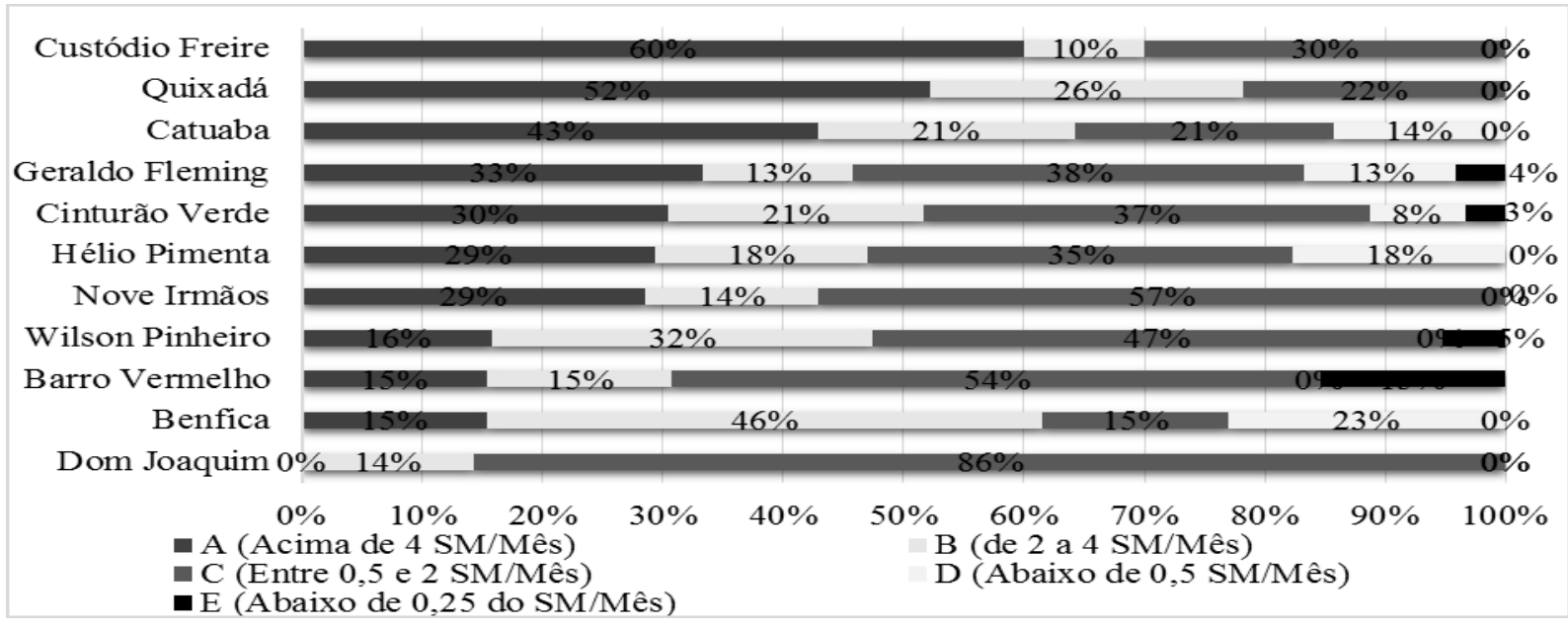

Fonte: ASPF (2017).

Do ponto de vista das rendas brutas recebidas pela produção de cada UPF, a Tabela 8 demonstra que as áreas do Custódio Freire e Quixadá têm as maiores rendas brutas medianas, com valores de $\mathrm{R} \$ 3.821,25$ e $\mathrm{R} \$ 3.731,67$, bem distantes da renda mediana auferida pelas famílias do Barro Vermelho, que recebem cinco vezes menos, em torno de R $\$ 750,75$. Ressalta-se ainda que, afora esta última área, todas as outras apresentam rendas medianas próximas ou superior a dois $\mathrm{SM} /$ mês.

Tabela 8 - Renda Bruta mensal, por UPF e área pesquisada, gerada entre produtores do Cinturão Verde de Rio Branco, Acre - 2015/2016.

\begin{tabular}{lccccc}
\hline \multirow{2}{*}{ Áreas Pesquisadas } & \multicolumn{3}{c}{ Renda Bruta - RB - (R\$/UPF/Mês) } & \multirow{2}{*}{ RB/SM } \\
\cline { 2 - 5 } & Produtos Prioritários & Outras Culturas & Criações & Total & \\
\hline Custódio Freire & $1.527,50$ & $1.343,75$ & 113,67 & $3.821,25$ & 4,34 \\
Quixadá & $1.827,30$ & $1.650,00$ & 250,00 & $3.731,67$ & 4,24 \\
Catuaba & $1.944,45$ & $2.833,00$ & 80,00 & $2.530,00$ & 2,88 \\
Benfica & $1.587,50$ & 325,17 & 150,00 & $2.187,50$ & 2,49 \\
Cinturão Verde & $\mathbf{1 . 3 4 3 , 3 3}$ & $\mathbf{5 0 9 , 1 7}$ & $\mathbf{1 9 3 , 7 5}$ & $\mathbf{1 . 9 6 8 , 1 3}$ & $\mathbf{2 , 2 4}$ \\
Geraldo Fleming & $1.363,00$ & 300,00 & 260,00 & $1.712,67$ & 1,95 \\
Hélio Pimenta & $1.112,67$ & 438,33 & 83,33 & $1.695,00$ & 1,93 \\
Wilson Pinheiro & 720,00 & 443,77 & 250,00 & $1.587,14$ & 1,80 \\
Nove Irmãos & $1.385,33$ & 486,67 & 297,00 & $1.477,00$ & 1,68 \\
Dom Joaquim & $1.229,40$ & 547,33 & 156,25 & $1.437,73$ & 1,63 \\
Barro Vermelho & 561,83 & 228,50 & 202,00 & 750,75 & 0,85 \\
\hline
\end{tabular}

Obs.: Produtos Prioritários: Banana, Melancia, Laranja, Limão, Mandioca, Farinha de Mandioca, Goma, Alface, Couve, Pimenta de Cheiro e Cheiro Verde; Valores medianos.

Fonte: ASPF (2017).

Além disso, do ponto de vista da evolução dos indicadores dos Polos Agroflorestais, nos últimos dez anos, a Tabela 9 apresenta que os produtos que mais contribuíram no aumento da renda bruta foram a banana, com $16 \%$ de evolução, e, principalmente, o couve e o

DRd - Desenvolvimento Regional em debate (ISSNe 2237-9029) 
cheiro verde, com $129 \%$ e $468 \%$, respectivamente. Esse aumento ocorreu, notadamente, pelo impacto do PAA na região.

Tabela 9 - Evolução da geração de Renda Bruta mensal, por produto prioritário nos Polos Agroflorestais, do Cinturão Verde de Rio Branco, Acre - Períodos 2005/2006 e 2015/2016.

\begin{tabular}{|c|c|c|c|}
\hline \multirow{2}{*}{ Grupo/Produto } & \multicolumn{2}{|c|}{ Renda Bruta (\%) } & \multirow{2}{*}{ Evolução (\%) } \\
\hline & $2005 / 2006$ & $2015 / 2016$ & \\
\hline Banana & $10 \%$ & $12 \%$ & $16 \%$ \\
\hline Melancia (Unidade) & & $2 \%$ & \\
\hline Laranja $(\mathrm{Kg})$ & & $2 \%$ & \\
\hline Limão $(\mathrm{Kg})$ & & $2 \%$ & \\
\hline Macaxeira (Kg) & $16 \%$ & $17 \%$ & $11 \%$ \\
\hline Farinha $(\mathrm{Kg})$ & & $1 \%$ & \\
\hline Goma $(\mathrm{Kg})$ & & $4 \%$ & \\
\hline Alface (Maço) & $8 \%$ & $7 \%$ & $-13 \%$ \\
\hline Pimenta de cheiro $(\mathrm{Kg})$ & $4 \%$ & $1 \%$ & $-64 \%$ \\
\hline Couve (Maço) & $5 \%$ & $10 \%$ & $129 \%$ \\
\hline Cheiro-verde (Maço) & $2 \%$ & $13 \%$ & $468 \%$ \\
\hline
\end{tabular}

Fonte: ASPF (2017).

$\mathrm{Na}$ Tabela 10, observa-se apreciável evolução na geração de renda bruta mediana entre os Polos Agroflorestais, no último decênio. Destacam-se os rendimentos auferidos pelas famílias do Custódio Freire, Dom Joaquim, Hélio Pimenta, que obtiveram evolução na renda de $141 \%, 134 \%$ e $73 \%$, respectivamente.

Tabela 10 - Evolução da Renda Bruta mensal, por UPF e áreas pesquisadas, gerada entre produtores do Cinturão Verde de Rio Branco, Acre - Períodos 2005/2006 e 2015/2016.

\begin{tabular}{lccc} 
& \multicolumn{2}{c}{ Renda Bruta (R\$/UPF) } & Evolução (\%) \\
\hline Áreas Pesquisadas & $\mathbf{2 0 0 5 / 2 0 0 6}$ & $\mathbf{2 0 1 5 / 2 0 1 6}$ & $141 \%$ \\
Quixadádió Freire & $1.588,09$ & $3.821,25$ & \\
Catuaba & & $3.731,67$ & \\
Cinturão Verde & & $2.530,00$ & $45 \%$ \\
Benfica & & $1.968,13$ & $73 \%$ \\
Hélio Pimenta & $1.509,02$ & $2.185,50$ & $53 \%$ \\
Geraldo Fleming & 979,36 & $1.695,00$ & $134 \%$ \\
Nove Irmãos & $1.119,27$ & $1.712,67$ & $23 \%$ \\
Dom Joaquim & & $1.477,00$ & \\
Wilson Pinheiro & 613,86 & $1.437,73$ & $1.587,14$ \\
Barro Vermelho & $1.289,91$ & 750,75 & \\
\hline
\end{tabular}

Fonte: ASPF (2017). Obs.: Valores medianos.

Mesmo assim, de acordo com a Tabela 11, 31\% das famílias do Cinturão Verde de Rio Branco-AC tiveram algum membro buscando assalariamento - como forma de complementação da renda bruta - fora da sua unidade produtiva, com a realização de diárias, empreitadas ou empregos fixos, como faxineiros, professores etc., com rendimentos medianos 
em torno de um salário mínimo mensal, levando-se em consideração o Cinturão Verde de Rio Branco-AC.

Ademais, $71 \%$ das famílias são beneficiadas por programas governamentais de transferência de renda, como o bolsa família e aposentadorias, cuja renda também gira em torno de um salário mínimo por mês.

Tabela 11 - Rendas de Assalariamento e Transferência Governamentais entre as famílias do Cinturão Verde de Rio Branco, Acre - 2015/2016.

\begin{tabular}{lcccc}
\hline \multirow{2}{*}{$\begin{array}{c}\text { Áreas } \\
\text { Pesquisadas }\end{array}$} & $\begin{array}{c}\text { Rendas de Assalariamento e Transferências (R\$/mês) } \\
\text { \% Famílias } \\
\text { com RA }\end{array}$ & $\begin{array}{c}\text { Renda de Assalariamento } \\
\text { (RA) }\end{array}$ & $\begin{array}{c}\text { \% Famílias } \\
\text { com RT }\end{array}$ & $\begin{array}{c}\text { Renda de Transferências } \\
\text { (RT) }\end{array}$ \\
\hline Quixadá & $18 \%$ & $1.545,00$ & $30 \%$ & 818,67 \\
Catuaba & $7 \%$ & $1.150,00$ & $27 \%$ & 120,00 \\
Hélio Pimenta & $4 \%$ & $1.009,33$ & $8 \%$ & 958,67 \\
Wilson Pinheiro & $13 \%$ & 909,33 & $60 \%$ & 818,67 \\
Dom Joaquim & $7 \%$ & 900,00 & $17 \%$ & 700,00 \\
Cinturão Verde & $\mathbf{3 1 \%}$ & $\mathbf{8 1 8 , 6 7}$ & $\mathbf{7 1 \%}$ & 155,00 \\
Nove Irmãos & $33 \%$ & 818,67 & $23 \%$ & 452,00 \\
Geraldo Fleming & $25 \%$ & 475,00 & $43 \%$ & 818,67 \\
Benfica & $28 \%$ & 341,67 & $37 \%$ & 818,67 \\
Barro Vermelho & $10 \%$ & 300,00 & $27 \%$ & 818,67 \\
Custódio Freire & $20 \%$ & 293,33 & $60 \%$ & \\
\hline
\end{tabular}

Fonte: ASPF (2017).

A Tabela 12 apresenta a distribuição das transferências de renda entre bolsa família e aposentadoria, que na região de estudo beneficiam entre $30 \%$ e $40 \%$ das famílias, com ênfase para o Polo Nove Irmãos, já que 56\% das famílias da região são beneficiárias dos programas sociais.

Tabela 12 - Rendas de Transferência Governamentais (bolsa família e aposentadoria) entre as famílias do Cinturão Verde de Rio Branco, Acre - 2015/2016.

\begin{tabular}{lcccc}
\hline \multirow{2}{*}{ Áreas Pesquisadas } & \multicolumn{4}{c}{ Rendas de transferências Governamentais } \\
\cline { 2 - 5 } & $\begin{array}{c}\text { \% Famílias - } \\
\text { (BF) }\end{array}$ & $\begin{array}{c}\text { RS - Bolsa Família } \\
\text { (BF) }\end{array}$ & \% Famílias - (Ap) & $\begin{array}{c}\text { R\$ - Aposentadoria } \\
\text { (Ap) }\end{array}$ \\
\hline Benfica & $4 \%$ & 540,00 & $30 \%$ & 818,67 \\
Hélio Pimenta & $1 \%$ & 205,00 & $7 \%$ & 818,67 \\
Barro Vermelho & $10 \%$ & 154,00 & $17 \%$ & 818,67 \\
Wilson Pinheiro & $27 \%$ & 154,00 & $30 \%$ & $1.637,33$ \\
Quixadá & $18 \%$ & 151,00 & $18 \%$ & $1.228,00$ \\
Cinturão Verde & $\mathbf{3 4 \%}$ & $\mathbf{1 5 0 , 0 0}$ & $\mathbf{3 8 \%}$ & 818,67 \\
Nove Irmãos & $56 \%$ & 150,00 & $7 \%$ & 759,33 \\
Dom Joaquim & $20 \%$ & 147,00 & $7 \%$ & 818,67 \\
Geraldo Fleming & $30 \%$ & 142,50 & $15 \%$ & 818,67 \\
Custódio Freire & $27 \%$ & 133,00 & $40 \%$ & $1.637,33$ \\
Catuaba & $17 \%$ & 112,00 & $3 \%$ & \\
\hline
\end{tabular}

Fonte: ASPF (2017).

DRd - Desenvolvimento Regional em debate (ISSNe 2237-9029) 
Na Tabela 13 são somadas todas as rendas medianas recebidas pelas famílias do Cinturão Verde de Rio Branco-AC, conformando na denominada Renda Bruta Total, que é o somatório das Rendas Bruta (Produção), de Assalariamento e de Transferências Governamentais. De forma geral, em termos medianos para a região, a pesquisa indicou que as famílias precisam rendimentos extras em torno de $45 \%$ a mais que o gerado de renda bruta na unidade produtiva. Vale notar as áreas com maiores dificuldades de geração de renda bruta, como é o caso do Barro Vermelho, com renda extra mediana de $60 \%$. Isto acontece porque as famílias, normalmente, buscam complementar a renda da sua unidade produtiva quando não conseguem comprar no mercado todas suas necessidades, apenas com a renda da produção.

Tabela 13 - Renda Bruta Total mediana auferida pelas famílias das áreas pesquisadas do Cinturão Verde de Rio Branco, Acre - 2015/2016.

\begin{tabular}{lccccc}
\hline $\begin{array}{c}\text { Áreas } \\
\text { Pesquisadas }\end{array}$ & $\begin{array}{c}\text { Renda } \\
\text { Bruta (RB) } \\
\mathbf{- A}\end{array}$ & $\begin{array}{c}\text { Renda de } \\
\text { Assalariamento } \\
\text { (RA) - B }\end{array}$ & $\begin{array}{c}\text { Renda de } \\
\text { Transferências } \\
\text { (RT) - C }\end{array}$ & $\begin{array}{c}\text { Renda Bruta } \\
\text { Total (RBT) - } \\
\text { A+B+C }\end{array}$ & $\begin{array}{c}\text { Renda Externa } \\
\text { (\%) }\end{array}$ \\
\hline Custódio Freire & $3.821,25$ & 293,33 & 818,67 & $4.933,25$ & $23 \%$ \\
Quixadá & $3.731,67$ & $1.545,00$ & 818,67 & $6.095,34$ & $39 \%$ \\
Catuaba & $2.530,00$ & $1.150,00$ & 120,00 & $3.800,00$ & $33 \%$ \\
Cinturão Verde & $\mathbf{1 . 9 6 8 , 1 3}$ & $\mathbf{8 1 8 , 6 7}$ & $\mathbf{8 1 8 , 6 7}$ & $\mathbf{3 . 6 0 5 , 4 7}$ & $\mathbf{4 5 \%}$ \\
Benfica & $2.185,50$ & 341,67 & 818,67 & $3.345,84$ & $35 \%$ \\
Hélio Pimenta & $1.695,00$ & $1.009,33$ & 958,67 & $3.663,00$ & $54 \%$ \\
Geraldo Fleming & $1.712,67$ & 475,00 & 452,00 & $2.639,67$ & $35 \%$ \\
Nove Irmãos & $1.477,00$ & 818,67 & 155,00 & $2.450,67$ & $40 \%$ \\
Dom Joaquim & $1.437,73$ & 900,00 & 700,00 & $3.037,73$ & $53 \%$ \\
Wilson Pinheiro & $1.587,14$ & 909,33 & 818,67 & $3.315,14$ & $52 \%$ \\
Barro Vermelho & 750,75 & 300,00 & 818,67 & $1.869,42$ & $60 \%$ \\
\hline Fonte: ASPF $(2017)$ & & & & &
\end{tabular}

Fonte: ASPF (2017).

No projeto ASPF, foi desenvolvido um indicador chamado de Linha de Dependência do Mercado (LDM), que é o somatório dos gastos efetuados com bens e serviços de consumo comprados no mercado - para alimentação, vestuário, energia etc., além da reposição dos capitais fixos, como terçados, máquinas etc. Infelizmente no presente trabalho não foi possível levantar, dados os objetivos e prazos, informações para a LDM da região. Portanto, como parâmetro de avaliação se tem a LDM do censo realizado nos Polos de Rio Branco-AC, pelo ZEAS de 2006/2007, cujo valor é de R\$ 1.506,47/mês - já atualizado para fevereiro/2017, pelo Índice Nacional de Preços ao Consumidor (INPC).

Desse modo, comparando a LDM com os valores da Renda Bruta Mediana, constantes na Tabela 13, percebe-se que apenas as famílias do Barro Vermelho precisam efetivamente de rendas complementares. Contudo, como os valores medianos apenas indicam que metade das famílias estão abaixo ou acima desses valores, é necessário um olhar mais detalhado sobre a situação das famílias em termos da suficiência dos rendimentos recebidos para os gastos no mercado.

$\mathrm{Na}$ Tabela 14 foi feita essa verificação. Primeiro, cabe observar que a renda bruta não é o indicador mais apropriado para a comparação com os gastos no mercado, previstos pela LDM, visto que as primeiras deduções da renda bruta são os custos de produção imediatos,

DRd - Desenvolvimento Regional em debate (ISSNe 2237-9029) 
identificados como custos variáveis. Com essa dedução se tem outro indicador denominado de Margem Bruta Familiar, que é embolsado pelo produtor para suas compras no mercado.

De acordo com a Tabela 14, considerando todo o Cinturão Verde de Rio Branco-AC, cerca de $43 \%$ das famílias não conseguem comprar todas suas necessidades no mercado (LDM), pois precisam complementar a renda da produção através de realização de diárias, empreitadas etc.

Tabela 14 - Relação entre os rendimentos obtidos e os gastos estimados no Mercado (LDM) nas áreas pesquisadas do Cinturão Verde de Rio Branco, Acre - 2015/2016.

\begin{tabular}{lcc}
\hline \multicolumn{1}{c}{ Áreas Pesquisadas } & Famílias com MBF < LDM (\%) & Famílias com RBT < LDM (\%) \\
\hline Barro Vermelho & $69 \%$ & $46 \%$ \\
Dom Joaquim & $57 \%$ & $14 \%$ \\
Nove Irmãos & $57 \%$ & $0 \%$ \\
Wilson Pinheiro & $50 \%$ & $33 \%$ \\
Hélio Pimenta & $47 \%$ & $12 \%$ \\
Geraldo Fleming & $46 \%$ & $17 \%$ \\
Cinturão Verde & $\mathbf{4 3 \%}$ & $\mathbf{1 6 \%}$ \\
Benfica & $38 \%$ & $8 \%$ \\
Catuaba & $36 \%$ & $7 \%$ \\
Custódio Freire & $30 \%$ & $10 \%$ \\
Quixadá & $22 \%$ & $4 \%$ \\
\hline Obs.: MBF representa $90 \%$ da Renda Bruta (RB); LDM $=\mathrm{R} \$ 1.506,47 /$ mês - Valor do período 2005/2006, \\
atualizado para Fevereiro/2017 pelo INPC.
\end{tabular}

Fonte: ASPF (2017).

Mas, preocupa ainda que $16 \%$ das famílias da região não conseguiram nenhum tipo de complementação de renda e não puderam comprar tudo o que precisavam no mercado. Além disso, tal preocupação se amplia quando se percebe algumas áreas com quantidade significativa de produtores enfrentando dificuldades para comprar o que precisa para a manutenção das famílias, como é o caso do Barro Vermelho e do Wilson Pinheiro, com 46\% e 33\%, respectivamente, das famílias nessa situação.

Claro que a superação da necessidade de complementar renda passa pelo aumento da produção e da produtividade e diversificação das unidades produtivas. Porém, isto leva tempo e dinheiro, juntamente com assistência técnica, acesso a crédito adequado etc. Enquanto isto não acontece, as famílias precisam resolver a situação imediatamente, pois as necessidades continuam lá. Assim, caso não consigam trabalhos temporários, a saída será vender bens, levando a perda de patrimônio; comprar fiado; pegar dinheiro emprestado, ou seja, endividamento. No final das contas, a última opção é vender sua propriedade para pagar as dívidas. 


\section{CONSIDERAÇÕES FINAIS}

Os Polos Agroflorestais foram instalados na década de 1990 pela Prefeitura Municipal de Rio Branco - AC na área rural do município, conhecida como Cinturão Verde, em resposta aos deficientes assentamentos de reforma agrária criados pelo Instituto Nacional de Colonização e Reforma Agrária.

Essa nova modalidade de assentamento foi criada com base no pressuposto do desenvolvimento sustentável, de forma que garanta a justiça social, a prudência ecológica e a eficiência econômica. Assim, um grande diferencial desse modelo de reforma agrária foi a priorização de assentar antigos moradores de seringais e colônias que foram desapropriados e não encontravam ocupações nas cidades.

Outro fator que destaca os Polos Agroflorestais dos assentamentos tradicionais é a localização das áreas. Todos os polos fazem parte do Cinturão Verde do município de Rio Branco e, consequentemente, apresentam maior proximidade com o mercado, tanto de escoamento da produção para a comercialização, como a maior facilidade de acesso a insumos e materiais.

A proximidade com a cidade garante também uma infraestrutura mais adequada para o desenvolvimento das famílias, visto a facilidade de manutenção dos ramais, disponibilidade de transporte público em alguns polos, a disponibilização de energia elétrica em todas as áreas etc.

O presente trabalho buscou verificar e comparar a distribuição de renda entre as famílias assentadas no Cinturão Verde do município de Rio Branco, considerando um intervalo temporal de dez anos, sendo os períodos 2005/2006 e 2015/2016. Ademais, verificou-se também como está a utilização da terra para entender se essa política de reforma agrária ainda vem cumprindo seu papel de sustentabilidade.

Do ponto de vista ambiental, identificou-se através dos resultados de uso da terra que as famílias assentadas nos polos vêm cumprindo seu papel de conservação, manutenção e recuperação das áreas nos últimos dez anos, em especial, pelo aumento das capoeira e florestas nas UPFs.

Entretanto, é preocupante notar que os sistemas agroflorestais estão sendo substituídos por atividades de monocultivos, notadamente de culturas perenes e roçados, uma vez que a monocultura é prejudicial ao solo.

Outro fator que desperta atenção é a evolução da utilização das áreas de pastagens, embora que sejam pequenas, a utilização essas áreas dobraram em um período de dez anos. Assim, no médio e longo prazo essa situação se expandirá e será um problema para a sustentabilidade ambiental dos polos.

Por outro lado, diante de uma breve análise produtiva, observou-se que os produtores familiares vêm apresentando uma acentuada diversificação produtiva, em particular com o expressivo aumento da produção de hortaliças, sendo uma atividade rentável e que não requer extensões de terras maiores, demonstrando maior equilíbrio no uso da terra. 
Em relação a questão econômica, também constatou-se o avanço produtivo de hortaliças no Cinturão Verde, a qual verificou - a partir da identificação dos produtos que compõem a geração de renda bruta - o impacto da produção e comercialização de mandioca e seus derivados e, principalmente, de hortaliças, que foi responsável pela participação de aproximadamente $30 \%$ do total de renda bruta gerada. A comparação com o período anterior, 2005/2006, mostrou que a ampliação da comercialização de couve e cheiro verde foram os principais representantes da expressiva participação de produtos da horticultura.

Um dos pontos decisivos para o crescimento da comercialização dos produtos dos Polos Agroflorestais foi o papel decisivo da participação do Programa de Aquisição de Alimentos (PAA), atuando de forma homogênea na região, notadamente como um regulador de mercado tanto em quantidade de produto comprado como em preço pago ao produtor. Entretanto, para verificar o impacto real dessa política são necessários estudos mais profundos e adequados na região a respeito desse tema.

A evolução da geração de renda bruta foi observada também na renda bruta mensal das famílias. Comparando com os resultados de dez anos atrás, verificou que houve uma evolução considerável nas rendas familiares em todos os Polos. Os rendimentos auferidos pelas famílias nos Polos Custódio Freire, Barro Vermelho, Dom Joaquim e Hélio Pimenta foram os que mais se destacaram.

A partir da análise econômica mediante o levantamento da comercialização da produção das UPFs dos Polos Agroflorestais foi possível verificar como está a distribuição de renda na região. Os resultados apontaram que existe uma alta disparidade dos valores da renda auferida pelas famílias e que de forma mediana apresentam um rendimento de 2,2 salários mínimos mensais.

Essa disparidade foi constada de uma forma mais específica através dos resultados do Índice de Gini, que mostrou de forma geral no Cinturão Verde o acompanhamento ao alto padrão brasileiro de concentração de renda. Entretanto, quando verificou-se os resultados individuais observou-se que existem Polos com índices mais baixos em consonância com os padrões de países desenvolvidos.

Na relação entre os $10 \%$ mais ricos e $50 \%$ mais pobres, confirmou a forte diferença entre as rendas auferidas pelas famílias. Em alguns Polos, como o Hélio Pimenta, identificouse que as UPFs mais ricas dessa área ganham quase $70 \%$ mais que a metade das famílias.

Por outro lado, um resultado animador foi a comparação com o período anterior, que nos últimos dez anos o índice de Gini mostrou uma redução acentuada na maioria dos Polos pesquisados, ou seja, trata-se de uma tendência de queda da desigualdade de renda para os próximos anos.

Outro fator que mostrou resultados favoráveis para a produção familiar rural do Cinturão Verde foi a baixa incidência de famílias que se encontram abaixo das linhas de pobreza e extrema pobreza e, em alguns polos, sequer apresentou-se famílias nessas faixas de renda.

Nesse aspecto, observa-se que os Polos Agroflorestais do município de Rio Branco$\mathrm{AC}$ ainda apresentam algumas dificuldades para o desenvolvimento de uma pequena parte das famílias e que necessita de atenção de políticas públicas para a erradicação por completo da 
pobreza nessa região, mas ainda sim vem mostrando que essa política de reforma agrária tem contribuído para a melhoria da distribuição de renda dessa população.

Além disso, o presente trabalho identificou que as famílias assentadas no Cinturão Verde têm adotado alternativas produtivas pautadas na sustentabilidade ambiental, buscando o equilíbrio no uso da terra e também uma diversificação produtiva, consorciando a criação de animais de pequeno porte e produção de culturas que não exigem extensas áreas de terras, apresentando-se como um modelo de desenvolvimento sustentável para a produção familiar rural acreana.

A distribuição de terra mediante o instrumento de reforma agrária utilizada pela Prefeitura de Rio Branco, acompanhada por política públicas específicas e adequadas para as famílias assentadas nos Polos Agroflorestais como a assistência técnica e, principalmente, a localização, revelaram que - mesmo os índices ainda se apresentarem em níveis elevados essa política de caráter fundiário e ambiental permitiu que produção familiar rural pudesse desenvolver socialmente e economicamente com uma tímida melhoria na distribuição de renda.

\section{REFERÊNCIAS}

ABRAMOVAY, R. Uma nova extensão para a agricultura familiar. In: SEMINÁRIO NACIONAL DE ASSISTÊNCIA TÉCNICA E EXTENSÃO RURAL, 1997, Brasília. Anais do Seminário Nacional de Assistência Técnica e Extensão Rural. Brasília: PNUD, 1997. $222 p$.

. Um novo contrato para a política de assentamentos. In: OLIVEIRA, Pedro M., (org.). Economia brasileira: perspectivas do desenvolvimento São Paulo: Ed. CAVC, 2005, p. 355-375.

ASPF. Análise Socioeconômica de Sistemas Básicos de Produção Familiar Rural no Estado Acre. 2017. Disponível em: <http://aspf.wordpress.com>. (Projeto de Pesquisa do Centro de Ciências Jurídicas e Sociais Aplicadas da UFAC).

ASSIS, R. L. Desenvolvimento rural sustentável no Brasil: perspectivas a partir da integração de ações públicas e privadas com base na agroecologia. Economia Aplicada, v.10, n. 1, p.7589, mar. 2006.

BARRETO, P. (org.). A pecuária e o desmatamento na Amazônia na era das mudanças climáticas. Ritaumaria Pereira; Eugênio Arima, Belém, PA: Instituto do Homem e Meio Ambiente da Amazônia, 2008.

BARROS, R. P.; HENRIQUES, R.; MENDONÇA, R. A estabilidade inaceitável: desigualdade e pobreza no Brasil. Rio de Janeiro: IPEA, 2001.

BERGAMASCO, S.M.P.P; NORDER, L.A.C. O que são os assentamentos. São Paulo: Brasiliense. 1996. (Coleção primeiros passos; 301). 
BUAINAIN, A. M.; ROMEIRO, A. R.; GUANZIROLI, C. Agricultura familiar e o novo mundo rural. Sociologias, Porto Alegre, a. 5, n. 10, p. 312-347, jul./dez. 2003,

CHAYANOV, A. V. La organisación de launidad económica campesina. Buenos Aires: Nueva Vision, 1974.

CMMAD. Nosso futuro comum. 2. ed. Rio de Janeiro: Editora da Fundação Getúlio Vargas, 1991.

COSTA, S. S. M. Caracterização ambiental da reserva extrativista Chico Mendes (AcreBrasil): subsídios ao plano de manejo. 2000. Tese (Doutorado em Ciências)-UFSC. Florianópolis, 2000.

DAMASCENO, N. P.; KHAN, A. S.; LIMA, P. V. P. S. O impacto do Pronaf sobre a sustentabilidade da agricultura familiar, geração de emprego e renda no Estado do Ceará. Revista Economia e Sociologia Rural, v. 49, n. 1, p. 129-156, 2011.

DENARDI, R. A. Agricultura familiar e políticas públicas: alguns dilemas e desafios para o desenvolvimento rural sustentável. Agroecologia e desenvolvimento rural sustentável, Porto Alegre, v. 2, n. 3, p. 45-62, jul./set. 2001.

DOMBEK, L. A. Autoconsumo e segurança alimentar em assentamentos rurais do Portal do Panorama. 2006. 220 p. (Dissertação de mestrado) - UNICAMP/FEA. Campinas, 2006.

FERREIRA, J. M. M. A luta política em torno da implementação do modelo de reforma agrária de mercado durante o governo Cardoso. In: STEDILE, João P. (Org.). A questão agrária no Brasil: debate sobre a situação e perspectivas da reforma agrária na década de 2000. São Paulo: Expressão Popular, 2013.

GAZOLLA, M.; SCHNEIDER, S. Qual "Fortalecimento" da Agricultura Familiar? Uma análise do Pronaf crédito de custeio e investimento no Rio Grande do Sul. Revista de Economia e Sociologia Rural, Piracicaba, SP, v. 51, n. 1, p. 45-68, jan/mar. 2013.

GRAZIANO NETO, F. Questão agrária e ecologia: crítica da moderna agricultura. Rio de Janeiro: Brasiliense, 1982.

GUANZIROLI, C. et al. Agricultura familiar e reforma agrária no século XXI. Rio de Janeiro: Garland, 2001.

HOFFMANN, R. Desigualdade da distribuição da renda no Brasil: a contribuição de aposentadorias e pensões e de outras parcelas do rendimento domiciliar per capita. Revista Economia e Sociedade, Campinas, v. 18, n. 1 (35), p. 213-231, abr. 2009.

HOFFMANN, R. A distribuição da renda no Brasil no período 1992-2001. Revista Economia e Sociedade, Campinas, v. 11, n. 2 (19), p. 213-235. 2002.

INSTITUTO BRASILEIRO DE GEOGRAFIA E ESTATÍSTICA (IBGE). Censo Agropecuário 2006. Brasil, Grandes Regiões e Unidades da Federação. Rio de Janeiro: MPOG, 2009. Disponível em: <http://www.ibge.gov.br/home/estatistica/economia/ agropecuaria/censoagro/default.shtm>._Acesso em: 07 nov. 2014. 
INSTITUTO NACIONAL DE COLONIZAÇÃO E REFORMA AGRÁRIA (INCRA). Base de dados dos projetos de reforma agrária do Brasil. 2017. Disponível em:

$<$ http://www.incra.gov.br/reforma-agraria/questao-agraria/reforma-agraria $>$. Acesso em: 03 jan. 2017.

INSTITUTO DE PESQUISA ECONÔMICA APLICADA. Resultados GINI. Brasília, 2017. Disponível em: <http://www.ipeadata.gov.br/>. Acesso em: 02 jan. 2017.

LIMA, D. M. A.; WILKINSON, J. (Org.). Inovação nas tradições da agricultura familiar. Brasília: CNPq/Paralelo 15, 2002.

LOPES, C. E.V. Avaliação socioeconômica dos sistemas de produção em assentamentos rurais no estado de Roraima: o caso do assentamento rural PAD - Anauá. 2009. 129 p. Dissertação (Mestrado Profissional em Ciências Econômicas) - Faculdade de Ciências Econômicas - UFRGS. Porto Alegre, 2009.

MACIEL, R. C. G. et al. Inovação, reforma agrária e agricultura familiar: o caso da produção de palmito no Projeto de Desenvolvimento Sustentável Bonal. Cadernos de Ciência \& Tecnologia, Brasília, v. 31, n. 3, p. 443-544, 2014.

MACIEL, R. C. G.; GOMES, K. P. C. C. Agricultura familiar no Acre: considerações a partir do censo agropecuário de 2006. Sociedade e Desenvolvimento Rural, Brasília, v. 7, n. 2, p. $1-15$, abr. 2013.

MACIEL, R. C. G; CAMPOS, K. P. da C.; SOUZA, E. F. de. Diagnóstico sócio-econômico da produção familiar rural nos Pólos Agroflorestais do Acre. In: CONGRESSO DA SOCIEDADE BRASILEIRA DE ECONOMIA, ADMINISTRAÇÃO E SOCIOLOGIA RURAL, 48. 2010, Campo Grande. Anais... Campo Grande: SOBER, 2010.

MACIEL, R. C. G. Ilhas de alta produtividade: inovação essencial para a manutenção dos seringueiros nas reservas extrativistas. 2003. 98p. Dissertação (Mestrado em Desenvolvimento Econômico, Espaço e Meio Ambiente) - UNICAMP. Campinas, 2003.

MATOS, J. D. Distribuição de renda: fatores condicionantes e comparação entre as regiões metropolitanas pesquisadas pela PED. Porto Alegre: FEE, 2005. (Documentos FEE; n. 62).

MOREIRA, R. J. Agricultura familiar e sustentabilidade: valorização e desvalorização econômica e cultural das técnicas. Estudos Sociedade e Agricultura, n. 8, p. 51-69, abr./1997.

NAVARRO, Z. Desenvolvimento rural no Brasil: os limites do passado e os caminhos do futuro. Estudos Avançados, São Paulo, v. 15, n. 43, p. 83-100, set./dez. 2001.

NEHMI FILHO, V. A. Para onde caminha a pecuária brasileira. p. 14-23. In: Anualpec 2005. Anuário da pecuária brasileira 2005. São Paulo: IFNP-AgraFNP, 2005.

NOGUEIRA, H. A. S.; SILVA, R. G. Análise espacial da desigualdade econômica na Região Norte do Brasil: um estudo das microrregiões. Revista de Estudos Sociais, Mato Grasso, n. 33, v. 17, p. 28, 2015. 
OLIVEIRA, L. S. Três ensaios sobre pobreza multidimensional. Rio de Janeiro, 2010. 123 p. Tese (Doutorado em Economia) - Programa de Doutorado em Economia, Universidade Federal do Rio de Janeiro. Rio de Janeiro, 2010.

PEREIRA. M. F. Política agrícola brasileira e a pequena produção familiar: heranças históricas e seus efeitos no presente. Revista Brasileira de Gestão e Desenvolvimento Regional, São Paulo, v. 6, n. 3, 2010.

PODOLESKI, S. O. Lei de Terras de 1850. Revista Santa Catarina em História, Florianópolis: UFSC, v. 1, n. 2, 2009.

RAMOS, P. Uma história sem fim: A persistência da questão agrária no Brasil contemporâneo. In: BUAINAIN, A. C. et al. (Ed.). O mundo rural no Brasil do século 21: a formação de um novo padrão agrário e agrícola. Brasília, DF: Embrapa, 2014, p. 655-693.

RÊGO, J. F.; COSTA FILHO, O. S.; BRAGA, R. A. da R. (Ed.). Análise econômica dos sistemas de produção familiar rural da região do Vale do Acre - 1996/1997. Rio Branco: UFAC/SEBRAE/The Ford Foundation, 2003.

RIVERO, S. et al. Pecuária e desmatamento: uma análise das principais causas diretas do desmatamento na Amazônia. Nova Economia Belo Horizonte, Belo Horizonte, v. 19, p. 41 66, jan./abr. 2009.

ROSA, M. A "Forma Movimento" como Modelo Contemporâneo de Ação Coletiva Rural no Brasil. In: FERNANDES, Bernardo M.; MEDEIROS, Leonilde S.; PAULILO, Maria I (Orgs.). Lutas camponesas contemporâneas: condições, dilemas e conquistas. v. 2: A diversidade das formas das lutas no campo. São Paulo: Editora UNESP; Brasília, DF: Núcleo de Estudos Agrários e Desenvolvimento Rural, 2009.

SACHS, Ignacy. Ecodesenvolvimento: crescer sem destruir. São Paulo: Vértice, 1986.

SANTOS, S. R. Q.; SOARES, N. S.; BENAVIDES, Z. A. C. Programa de Aquisição de Alimentos da Agricultura Familiar (PAA): O Caso dos Produtores de Ibicaraí-BA. Revista de Estudos Sociais. v. 17, n. 33. p. 161-182, 2015.

SALLES FILHO, S.; SOUZA, A. C. Agricultura familiar e investimento em desenvolvimento tecnológico. In: LIMA, Dalmo M. de Albuquerque; WILKINSON, John (Org.). Inovação nas tradições da agricultura familiar. Brasília: CNPq: Paralelo 15, 2002, p. 39-46.

SCHNEIDER, S.; CASSOL, A. Diversidade e Heterogeneidade da Agricultura Familiar no Brasil e Algumas Implicações para Políticas Públicas. Cadernos de Ciência \& Tecnologia, Brasília, v. 31, n. 2, p. 227-263, 2014.

SEN, A. Desenvolvimento como liberdade. São Paulo: Companhia das Letras, 2000.

SILVA, M. O. S. e. Pobreza, desigualdade e políticas públicas: caracterizando e problematizando a realidade brasileira. Revista Katálysis, Florianópolis, Ensaio, v. 13, n. 2, p. 155-163, 2010. 
SOARES, S. S. D. O ritmo na queda da desigualdade no Brasil é aceitável? Revista de Economia Política, São Paulo, v. 30, n. 3 (119), p. 364-380, jul./set. 2010.

Metodologias para estabelecer a linha de pobreza: objetivas, subjetivas, relativas, multidimensionais. Rio de Janeiro, 2009. (Texto para discussão; n. 1381).

SOUZA, E. F. Os polos agroflorestais como política de desenvolvimento rural sustentável em Rio Branco no Acre: da proposição à realidade., 2008. 180 p. Dissertação (Mestrado em Economia Doméstica) - Universidade Federal de Viçosa. 2008. Viçosa: DED/UFV, 2008.

SOUZA FILHO, H. M. et al. Condicionantes da adoção de inovações tecnológicas na agricultura. Cadernos de Ciência \& Tecnologia, Brasília, v. 28, n. 1, p. 223-255, jan./abr. 2011.

VEIGA, J. E. O Brasil rural ainda não encontrou seu eixo de desenvolvimento. Estudos Avançados, Rio de Janeiro, v. 15, n. 43, 2001.

Desenvolvimento sustentável: o desafio do século XXI. 3. ed. Rio de Janeiro: Garamond, 2008.

WANDERLEY, M. N. B. Raízes históricas do campesinato brasileiro. In: TEDESCO, J.C. (Org.). Agricultura familiar: realidades e perspectivas. Passo Fundo: EDIUPF, 2001, p. 23 56.

Agricultura familiar e campesinato: rupturas e continuidade. Estudos Sociedade e Agricultura, Rio de Janeiro, n. 21, p. 42-61, out. 2003.

ZEAS. Zoneamento Econômico, Ambiental, Social e Cultural: diagnóstico dos polos agroflorestais. Rio Branco, 2008. Disponível em: $<$ http://zeas.riobranco.ac.gov.br/>. Acesso em: 16 jan. 2017.

Artigo recebido em: 07/03/2017

Artigo aprovado em: 25/06/2018 